\title{
Labour Market Status and Migration Dynamics
}

\author{
Govert E. Bijwaard* \\ Netherlands Interdisciplinary Demographic Institute (NIDI) and IZA
}

September 28, 2009

* Netherlands Interdisciplinary Demographic Institute (NIDI), PO Box 11650, 2502 AR The Hague, The Netherlands; Phone: (+31) 703565 224; Fax: (+31) 70 3647187; E-mail: bijwaard@nidi.nl This research is based on a collaboration with Statistics Netherlands and financially supported by the Netherlands Organization for Scientific Research (NWO) nr. 451-04-011. I thank Ruben van Gaalen and Steffen Reinhold for valuable comments. I also benefited from seminars in Mannheim, Tartu, Alicante and The Hague. 


\title{
Labour Market Status and Migration Dynamics
}

\begin{abstract}
In this empirical paper we assess how labour market transitions and out- and repeat migration of immigrants are interrelated. We estimate a multi-state multiple spell competing risks model with four states: employed, unemployed receiving benefits, out-of-the-labour market (no benefits) and abroad. We discuss one-step ahead transitions from all four states and the transition probability, including all intermediate transitions, from employment. Based on the estimated parameters we simulate the labour-migration dynamics for a synthetic cohort to derive relevant economic indicators, e.g. the probability of experiencing an unemployment spell.

For the analysis we use data on recent labour immigrants to The Netherlands, which implies that all migrants are (self)-employed at the time of arrival. We find that many migrants leave the country after a period of no-income. Employment characteristics and the country of origin play an important role in explaining the dynamics. The microsimulations of synthetic cohorts reveal that many migrants experience unemployment spells, but ten years after arrival only a few are unemployed. They also indicate that the Credit Crunch will not only increase the unemployment among migrants but also departure from the country. An increase in the number of migrants from the EU accession countries will lead to more dynamics. We do not expect that the recent simplification of the entry of high income migrants will have a lasting effect, as many of those migrants leave fast.
\end{abstract}

JEL classification: F22, J61, C41.

Key words: migration dynamics; labour market transitions; competing risks; immigrant assimilation; 


\section{Introduction}

Many European countries see immigration as a potential solution to the social security crisis induced by an aging population, rising health costs and low fertility rates. Immigration of young workers slows down the aging of the population. However, immigrants can become a financial burden on the host country if they get unemployed fast and draw on the social insurance systems, see Storesletten (2000). They could potentially make an important contribution to the social security system of the host country. Whether immigrants become a burden depends on their labour market status and how this changes over time. In principle, only working immigrants contribute financially to the host country. Unemployed migrants draw on the social security system of the host country. However, many migrants have not gained any right on social security benefits and these non-participating migrants therefore neither contribute nor draw on the host country economy.

Whether immigrants become a burden also depends on their migration dynamics in relation to their labour market status. If out-migration is selective on the most economically successful immigrants, the host country looses potential contributors. But, if out-migration is selective on unemployed or out-of-the labour market immigrants, the host country gains from such migration, see Kirdar (2009). The story does not end with out-migration as a small, but significant, percentage of the out-migrated immigrants returns to the host (6\% within five years in The Netherlands, see Bijwaard (2010)). Some return-out-migrants still have the right to receive social security benefits. From a host country perspective it is preferred that the employed migrants, or at least those who do not place a financial burden on the national social security system, return to the host and the others remain abroad. This leads to a perpetual tale of intercorrelated labour market behaviour and migration dynamics.

Much of the theoretical and empirical literature on the economics of migration views migrations as permanent. This is a convenient assumption and often facilitates the analysis of immigrant behaviour and the impact of migration on the host country. Jasso and Rosenzweig (1982) already argued that many migrations are temporary rather than permanent. For labour migrants migration dynamics are intertwined with their labour market behaviour, as loosing their job may induce them to search for another job in another country. To gain insight in the migration dynamics of labour migrants, it is, therefore, imperative to include their dynamic behaviour on the host country's labour market.

Some studies have analyzed the labour dynamics of immigrants. For example, Chiswick et al. (1997) find that for the US that immigrants had some initial difficulty finding work, but their employment and unemployment rates quickly attained levels comparable to those of natives. Uhlendorff and 
Zimmermann (2006) study the German case and find that immigrants stay unemployed longer than natives. There is also some empirical evidence that an increasing number of immigrants are beneficiaries of welfare programs. Borjas and Hilton (1996) find that in the US the immigrant-native difference in the probability of receiving benefits is small. Hansen and Lofstrom (2003) find for Sweden that immigrants use welfare to a greater extend than natives. Hansen and Lofstrom (2009) analysed the dynamics across the labour market states of an immigrant. They find that (refugee) immigrants display a higher degree of state dependence in welfare. However, to our knowledge, no study has analyzed labour market dynamics of immigrants in relation to return (and repetitive) migration behaviour.

Bijwaard (2010) has shown that the migration motive influences the migration dynamics of immigrants. A unique feature of the data from Statistics Netherlands used for his article is that information on the motive to migrate is available for recent non-Dutch, non-national, migrants. Here we use a subset of the data by focussing on labour migrants, immigrants who are reported labour migrants and who are (self-)employed at their first entry. Explicit focus on labour migrants is unusual in the literature. In many studies the issue of migration motive is not addressed (e.g. Borjas 1999).

The data further contain information on the timing of migration moves. A difference with Bijwaard (2010) is that the data now includes, on a monthly basis, the labour market status and income of the migrants. The timing of both labour market status changes and migration status changes allows us to construct the labour market behaviour of the migrants together with their migration history. The duration in each labour market state forms the basis of our analysis. Duration, or event history, models have been used extensively for demographic analysis, for example in modelling time till birth of first child, time till marriage or time till death. However, the number of empirical duration analyses of migration decisions is rather limited and duration analysis of return migration is even more scarce. A few exceptions are Waldorf and Esparza (1991), Detang-Dessendre and Molho (1999), Longva (2001) and Constant and Zimmermann (2003). Most migration data lack information on the exact timing of the migration moves and only reveal whether the migrant is still in the country at the interview date.

Bijwaard (2010) estimated a mover-stayer duration model, which allows for both permanent and temporary immigrants, based on demographic data of immigrants to the Netherlands. He showed that the migration dynamics of these immigrants is substantial and that these dynamics heavily depend on the migration motive and the country of origin. In this article we focus on labour migrants and include data on social-economic variables of these migrants. Another difference is that we also consider the dynamic behaviour of the immigrants on the host country labour market.

We consider three labour market states, employment (including self-employment), receiving ben- 
efits (mainly unemployment benefits) and no-income in the host (or non-participating). We view the migrant behaviour as a semi-Markov process with individuals moving among the three labour states and abroad. We model the transition from each state as a competing risk duration model. For estimation we assume that the transition intensities for each competing risk are mutually independent. A problem with competing risks models is the interpretation of the parameters, because a particular covariate may appear in several intensities. Therefore, the results of the models are reported in terms of marginal effects on the exit probability. The marginal effect have a simple closed form solution because we use competing risks models with piecewise constant baseline hazards and discrete unobserved heterogeneity, see Kyyrä (2009).

A labour migrant may, as we observe in our data, first become non-participating before leaving the country. However, the exit probability only looks one step ahead and, therefore, only gives an incomplete picture of the dynamic behaviour of the immigrants. In order to look further ahead we calculate the transition probabilities, that take all the intermediate transitions into account, from employment. Again we report the marginal effects of the observed migrant characteristics on the transition probability.

Still a great deal of information on the behaviour of the immigrants is hidden when we report the transition probabilities. Important indicators of economic assimilation, as the number of unemployment spells or the length of unemployment spells cannot analytically be derived from the transition probabilities. However, based on the estimated parameters of the combined multistate multiple spell competing risk models we can simulate a synthetic cohort of migrants that provide us with many indicators that pertain to the length and number of spells in a particular state. Additionally, such microsimulation can, by changing the start population, provide us results for different scenario's concerning future migrant behaviour. We consider three alternative scenario's. The first scenario assumes an increase in the national unemployment rate from $3.1 \%$ to $6 \%$, as is currently encountered due to the Credit Crunch. The second scenario assumes that the number of immigrants from the EU accession countries, the countries that joined the EU in 2004, quadruples. This has happened in The Netherlands from 2002 to 2007. The final scenario assumes an increase in the inflow of high income ( $>€ 5000$ per month) with $50 \%$. This could be the effect of a recently implemented Dutch policy that simplifies entry of these migrants.

The outline of the paper is as follows. In the next section we shortly review the relevant economic theory on (return) migration and on labour market performance of immigrants. In Section 3 we discuss estimation and inference in a multi-state multiple spell competing risks model. In Section 4 we present 
the data and discuss the recent migrant history to the Netherlands. Section 5 gives the empirical results on the one-step ahead and transition probabilities. Section 6 provides the microsimulation of the base and alternative scenario's. Section 7 summarizes the results and states our conclusion.

\section{Conceptual framework}

Much of the economic research considers migration as permanent (see a.o. Chiswick 1978, Massey et al. 1993 and Borjas 1999). Nevertheless, the level of return migration has been high both in the US and in Europe. Jasso and Rosenzweig (1982) report that of 1971 cohort of immigrants to the US, almost fifty percent returned by 1979. Dustmann (1995) has demonstrated the relevance of return migration in the European context. In The Netherlands recent migrants also show a high return rate, see Bijwaard (2010). The return rates greatly differ by migration motive, with students and labour migrants having the fastest departure rate.

An important contribution to the theoretical explanations of return emigration of immigrants is provided by Borjas and Bratsberg (1996). They attribute return migration to an optimal residential local plan over the life cycle where immigrants return to source countries due to the realization of a savings goal or due to erroneous information about economic opportunities in the host country. Other theories attribute return migration to region-specific preferences (Hill 1987; Dustmann and Weiss 2007), higher purchasing power of host currency in source countries (Dustmann and Weiss 2007) or to greater returns for human capital acquired in the host country (Borjas and Bratsberg 1996; Dustmann and Weiss 2007). Borjas and Bratsberg (1996) also show that the selection of emigrants from a particular country reinforces the initial selection of immigrants to that country. Return migration may also be the result of unexpected events either information. It should also be noted that the boundary between between temporary and permanent migrants is not impermeable, see Berninghaus and Seifert-Vogt (1988).

Repeated migration occurs more often when we consider internal migration within a particular country. From the literature on internal migration we know that migration history has a systematic effect upon migration behaviour. For example, DaVanzo (1983) finds that those who have moved before are much more likely to move again (see also Constant and Zimmermann (2003)). Bailey (1993) shows that repeated migration of young adults within the US is a selective process, as it makes them less responsive to national unemployment conditions than first time migrants. He also finds that the timing of unemployment within the sojourn has a critical influence upon migration behaviour. For international migration the relation between unemployment experience and migration behaviour 
is more complex.

The analysis of repeated migration should not be separated from the labour market performance of the migrants in the host country. In the economic literature on migrant performance the focus has mainly been on the earnings of immigrants (Chiswick 1978, Borjas 1999). Much of this literature tends to emphasize the importance of earnings convergence, i.e. the effect of the time since arrival on the earnings difference with native workers. A major flaw of this literature is that it ignores the endogeneity of return migration, with Constant and Massey (2003) as one of the exceptions. Another issue is that earnings of the migrants only tell a part of the performance tale of the labour market outcomes. The incidence of unemployment among immigrants also plays an important role. For the analysis of this labour market outcome it is also important to account for selective out-migration. For policy makers it is of particular interest to know whether unemployment of a migrant induces out-migration or to stay longer and drawing on the host country social security system.

A few studies have analysed the transitions migrants make on the labour market. Uhlendorff and Zimmermann (2006) investigate the unemployment experiences of migrants in Germany. They take the temporal dependence of unemployment and employment spells into account. Borjas and Hilton (1996) find that in the US the immigrant-native difference in the probability of receiving benefits is small. Hansen and Lofstrom (2009) analysed the dynamics across the labour market states of an immigrant with an emphasize on welfare. However, they ignore possible selective out-migration. However, no study has taken the possible selective out-migration into account. Kirdar (2008) shows that unemployment has a profound effect on the timing of out-migration, but he ignores to take the route to unemployment into account. The contribution of this article is that we take an integrated view on labour market status and migration dynamics. By modeling the timing of both labour market changes and migration moves together we take the whole labour market history and the migration dynamics into account. In this article we focus on labour migrants only.

Information on the host country's labour market is crucial for success. The information problem for migrants may be bigger the further, both in distance and in culture, the host and source are apart. Furthermore migrants from further away could possess less host country specific human capital upon arrival. There is a considerable body of evidence that distance matters in deterring migration, see Long et al. (1988). The opportunity cost of remaining in the host are lower for countries close by. For example, Borjas and Bratsberg (1996) find that immigrants to the US tend to return to rich and to countries close to the US. Ethnicity is also important if immigrants of a certain ethnic group systematically perceive a lower return than expected. For immigrants belonging to such groups 
the re-migrate rate is higher. On the other hand, human capital accumulation in the host may be more in demand in countries similar to the host. For example, for the Netherlands the demand of high-skilled workers in other EU-countries or in the US is relevant for the re-migrate rate of these workers. This may lead to higher return- and re-immigration rates for immigrants from countries close to the Netherlands. Another issue is that immigrants from some countries may find it easier to migrate than other. An example is that citizens of EU-countries are formally allowed to migrate to and to work in other EU-countries. Following this argument EU-citizens should have a higher return and re-immigration rate than none EU-citizens.

Most labour migrants work for a company, while some migrants start their own business. These self-employed migrants need to invest more in the new country to be successful. This may lead to a higher attachment to the new labour market. It is therefore important to distinguish between selfemployed and company-employed migrants. Different sectors of the economy attract different types of migrants. We expect that migrants working in a sector in which temporary contracts are very common have less attachment to the new labour market. Those migrants may leave fast. The labour market behaviour in each sector may also differ, as employment in some sectors, notably temporary services and agriculture, is less stable.

In the literature opposing theories exist on the impact of the income level of migrants in the host country on their return propensity, see Constant and Massey (2003). Neoclassical Economics (NE) view return migration as a cost-benefit decision, maximizing expected lifetime income. According to this view return migrants are "failures" and low income migrants are more prone to return. The alternative New Economics of Labour Migration (NELM, Stark 1991) theory views migration as a response to market failures at home. According to this theory, people seek to migrate abroad temporarily to accumulate savings. They view migrants as target earners who return home after their target is reached. Thus, NELM views return migrants not as failures, but as "successes", and high income migrants would return faster. Many recent migrants have not yet gained any right on security benefits, because their duration of stay is too short. These migrants could be without income when they loose their job. The two theories do not exclude migrants that are temporary without income (from the host) remain in the host. Under NE the migrant may expect to return back to work and the period of income is just a friction. Under NELM the migrant remains because the target has not yet been reached.

Another important issue is whether the timing of arrival has a permanent effect on the labour market status of immigrants. Does arriving in the host country in a period of high unemployment, in 
which prospects for good jobs for new immigrants are scarce, place the immigrant in an unfavourable long-term employment situation? A related question is whether the selectivity of labour immigrants, controlling for personal and job characteristics and country of origin, varies over the business cycle. Are immigrants who arrive in a recession more favourably selected, perhaps because only the most able migrate when jobs are scarce? The scarring effect can be measured by including the analysis a variable for the unemployment rate in the economy the moment the immigrant arrives in the the host country.

\section{A competing risks model}

For both the labour market and the migration dynamics the timing of the transitions and the time between transitions is crucial. In a duration model the timing of a particular event (or recurrent event) is modeled. Another reason to apply duration models is that many relevant characteristics, like for example income and marital status, of the migrant may change over time. In duration models it is straightforward to incorporate such time-varying variables. We view the migrant behaviour as a semi-Markov process with individuals moving between four states. The four states identified in this paper are:

1. Employed in the host country;

2. Unemployed and receiving benefits in the host country;

3. Out of the labour market (and not receiving benefits= non-participating) in the host country;

4. Living abroad.

These states are mutually exclusive and exhaust all possible destinations. A migrant may leave a state $j=1, \ldots, 4$ for any of the other destination states, i.e. for $j=1$ the destination states are $k=2,3,4$, for $j=2 k=1,3,4$ etc.

For simplicity we assume that all spells are independent of each other. We use a competing risks model hazard model for each origin-destination pair. Define the random variables $T_{j k}$ that describe the time since entry in $j$ for a transition from $j$ to $k$. We assume a mixed proportional hazard model for which the intensity for the transition from $j$ to $k$ is:

$$
\lambda_{j k}\left(t \mid \bar{X}_{j k}(t), V_{j k}\right)=\lambda_{0 j k}(t) \exp \left(\beta_{j k}^{\prime} X_{j k}(t)+V_{j k}\right)
$$

where $\bar{X}_{j k}(t)=\left\{X_{j k}(s) \mid 0 \leq s \leq t\right\}$ is the sample path of the observed characteristics up to time $t$, which is, without loss of generality, assumed to be left continuous. The unobserved heterogeneity $V_{j k}$ 
also enters the intensity multiplicatively. We assume that the path of the observed characteristics is independent of the unobserved heterogeneity. The positive function $\lambda_{0 j k}(t)$ is the baseline intensity and we assume that it is piecewise constant on $H$ intervals ${ }^{1}$, i.e. $\lambda_{0 j k}(t)=\sum_{h=1}^{H} e^{\alpha_{j k h}} I_{h}(t)$ with $I_{h}(t)=I\left(t_{h-1} \leq t<t_{h}\right)$ and $t_{0}=0, t_{H}=\infty$. Any duration dependence can be approximated arbitrarily closely by increasing the number of intervals. The integrated intensity for a transition from $j$ to $k$ at duration $t$ is (conditional on $V$ )

$$
\Lambda_{j k}\left(t \mid \bar{X}_{j k}(t), V_{j k}\right)=\sum_{h=1}^{H} e^{\alpha_{j k h}+\beta_{j k} X_{h}+V_{j k}}\left(t_{h}-t_{h-1}\right) J_{h}(t)+\sum_{h=1}^{H} e^{\alpha_{j k h}+\beta_{j k} X_{h}+V_{j k}}\left(t-t_{h-1}\right) I_{h}(t)
$$

with $J_{h}(t)=I\left(t>t_{h-1}\right)$ and we assume that the change in the time-varying components of $X$ only occur at the discrete time and that the $H$ intervals also capture these changes. Thus $x_{h}$ is the value of $x$ in interval $\left[t_{h-1}, t_{h}\right)$.

For each origin state only the smallest of $T_{j k}$ durations $\tilde{T}_{j}=\min _{k} T_{j k}$ and the corresponding actual transition destination are observed. The other durations are censored, in the sense that all is known that their realisations exceed $\tilde{T}_{j}$. Suppose for individual $i$ we observe $M_{i j k} j$ to $k$ transition spells, at sojourn times $t_{1}, \ldots, t_{M}$, then the likelihood for these $M_{i j k}$ transitions is:

$$
L_{j k}=\int \prod_{m=1}^{M_{i j k}} \lambda_{j k}\left(t_{m} \mid \bar{X}_{j k}\left(t_{m}\right), V_{j k}\right)^{\delta_{m j k}} \exp \left(-\sum_{g \neq j} \Lambda_{j g}\left(t_{m} \mid \bar{X}_{j g}\left(t_{m}\right), V_{j g}\right)\right) d H_{j k}\left(V_{j k}\right)
$$

where $\delta_{m j k}=1$ for a $j$ to $k$ transition and 0 otherwise, $\Lambda_{j k}\left(t_{m} \mid \bar{X}_{j k}\left(t_{m}\right), V_{j k}\right)=\int_{0}^{t_{m}} \lambda_{j k}\left(s \mid \bar{X}_{j k}(s), V_{j k}\right) d s$, the integrated intensity. $H_{j k}\left(V_{j k}\right)$ is the distribution function of the unobserved heterogeneity, which we assume to be a discrete distribution with two points of support, $\left(v_{1 j k}, v_{2 j k}\right)$ and $\operatorname{Pr}\left(V_{j k}=v_{1 j k}\right)=$ $p_{j k} \cdot{ }^{2}$

For each origin destination pair the parameters are estimated separately. In other words, we assume that the transition intensities for each competing risk are mutually independent. This implies that the spell specific unobserved heterogeneity $\left(V_{j k}\right)$ are uncorrelated across the origin-destination pairs.

\footnotetext{
${ }^{1}$ It is not necessary that each baseline intensity changes at the same durations. Here $H$ is the total number of intervals considered. If for the transition from $j$ to $k$ the baseline intensity remains the same in $I_{h}(t)$ and $I_{h+1}(t)$ we have $\alpha_{j k h}=\alpha_{j k h+1}$.

${ }^{2}$ We estimate $\left(\exp \left(v_{1 j k}\right), \exp \left(v_{2 j k}\right)\right)$ and $q_{j k}$ with $p_{j k}=e^{q_{j k}} /\left(1+e^{q_{j k}}\right)$ and leave out the constant in the baseline intensity.
} 


\subsection{Inference in competing risks models}

The interpretation of the coefficients in a competing risks model requires caution. ${ }^{3} \mathrm{~A}$ particular covariate, say $x_{l}$, can appear in several intensities. In such a case the vectors $\beta_{l j k}$ convey little information about the effect of the covariate on the probability to exit from origin $j$ to destination $k$. The reason is that the exit probability not only depends on the intensity of making a transition to $k$ but also on the transition intensities to all other states.

The issue of difficult interpretation of covariate effects also arises in many other non-linear models, like the multinomial logit and probit models (see a.o. Cameron and Trivedi (2005), chapter 15). The results of such models are, therefore, usually reported in terms of the marginal effects on the probability of interest. Thomas (1996) and Kyyrä (2009) argue that a similar practice is useful in the context of competing risks models. Although the marginal effects eliminate much of the confusing about the interpretation of the results form competing risks models, they have rarely been computed. A drawback is that in general the marginal effects have no analytical solution, making their computation demanding and statistical inference difficult. Kyyrä (2009) shows that simple closed form solutions exist for the competing risks models with piecewise constant baseline hazards and discrete unobserved heterogeneity, exactly the model formulation we assume.

First, we discuss the total survival and the cumulative incidence function. Together they provide the distribution over the states at a particular sojourn time from each origin state. The total survival function from origin $j$ is

$$
S_{j}\left(t \mid \bar{X}_{j k}(t)\right)=\operatorname{Pr}\left(\tilde{T}_{j} \geq t\right)=\prod_{l \neq j} \int \exp \left(-\Lambda_{j l}\left(t \mid \bar{X}_{j l}(t), V_{j k}\right)\right) d H_{j l}\left(V_{j l}\right)
$$

The total survival gives the probability of starting in origin $j$ and stay there till for at least a duration t. For instance, the total survival for an employed migrant gives the probability to remain employed up to a given time. The cumulative incidence function is the probability of making a transition from $j$ to $k$ before duration $t$. Conditional on unobserved heterogeneity the cumulative incidence can be

\footnotetext{
${ }^{3}$ Note that in a standard mixed proportional hazard (MPH) model the interpretation of the coefficients is also not so clear. In a MPH model the regression coefficient of covariate $x_{l}$ is only defined conditional on the unobserved heterogeneity.
} 
expressed as

$$
\begin{aligned}
F_{j k}\left(t \mid \bar{X}_{j k}(t), V_{j k}\right)= & \operatorname{Pr}\left(\tilde{T}_{j} \leq t, \text { destination } k\right)=\int_{0}^{t} \lambda_{j k}\left(s \mid \bar{X}_{j k}(s), V_{j k}\right) S_{j}\left(s \mid \bar{X}_{j k}(s), V_{j k}\right) d s \\
= & \sum_{h=1}^{H} \pi_{j k}^{h}\left(X \mid V_{j k}\right)\left[S\left(t_{h-1} \mid \bar{X}_{j l}(t), V_{j k}\right)-S\left(t_{h} \mid \bar{X}_{j l}(t), V_{j k}\right)\right] J_{h}(t) \\
& +\sum_{h=1}^{H} \pi_{j k}^{h}\left(X \mid V_{j k}\right)\left[S\left(t_{h-1} \mid \bar{X}_{j l}(t), V_{j k}\right)-S\left(t \mid \bar{X}_{j l}(t), V_{j k}\right)\right] I_{h}(t)
\end{aligned}
$$

where $\pi_{j k}^{h}\left(X \mid V_{j k}\right)$ denotes the probability of exit from $j$ to $k$ in interval $\left[t_{h-1}, t_{h}\right)$ conditional on exiting and $S\left(t_{h-1} \mid \cdot\right)-S\left(t_{h} \mid \cdot\right)$ is the probability of exiting $j$ during the interval $\left[t_{h-1}, t_{h}\right)$. Integrating out the discrete unobserved heterogeneity we obtain

$$
F_{j k}\left(t \mid \bar{X}_{j k}(t)\right)=\sum_{q} \operatorname{Pr}\left(V_{j}=V_{j}^{q}\right) F_{j k}\left(t \mid \bar{X}_{j k}(t), V_{j}^{q}\right)
$$

with $V_{j}=\left\{V_{j k}, k \neq j\right\}$ and the sum is over all possible realizations of $V_{j}$ (eight in our application with a 2-point discrete unobserved heterogeneity distribution and three exit states). Thus, the cumulative incidence function from employment gives the probability to leave employment either to unemployment, to non-participation or to abroad before a given time spent in employment. Note that $\sum_{k \neq j} F_{j k}(t \mid \cdot)=1-S_{j}(t \mid \cdot)$.

The probability of ever exiting from $j$ to $k, \pi_{j k}(x)$, is the limit of the cumulative incidence function. It is easy to derive that with discrete unobserved heterogeneity and piecewise constant baseline intensities we have

$$
\pi_{j k}(x)=\sum_{q} \operatorname{Pr}\left(V_{j}=V_{j}^{q}\right) \frac{\exp \left(\alpha_{j k^{H}}+\beta_{j k} X_{H}+V_{j k}^{q}\right)}{\sum_{l=1}^{K} \exp \left(\alpha_{j l^{H}}+\beta_{j l} X_{H}+V_{j l}^{q}\right)}
$$

Kyyrä (2009) derives the marginal effects of $S_{j}(t \mid \cdot), F_{j k}(t \mid \cdot)$ and $\pi_{j k}(\cdot)$ of a variable $x_{l}$. In principle many marginal effects can be defined, depending on the values of the covariates (or path for timevarying covariates). The marginal effects of the first two functions also depend on the duration. We choose only to report the marginal effects of the exit probability, which does not depend on the duration. It is common to define the marginal effects w.r.t. the average individual, but marginal effects w.r.t. the reference individual are closer to ordinary coefficient interpretation. In our analysis most of the covariates are binary and the marginal effect of a covariate is simply $\Delta \pi_{j k}\left(x_{l}\right)=\pi_{j k}\left(t \mid x_{l}=\right.$ 1) $-\pi_{j k}(t \mid 0)$.

\subsection{Transition probabilities}

The total survival, cumulative incidence function and exit probability only give an incomplete picture of the dynamics of the migrants, as they just look one event ahead. In order to look further ahead, 
we need to take all the transitions into account. An employed migrant may, as we observe in our data, first become non-participating before he leaves the country. Another possible route to leave the country is through unemployment and non-participation, in either way. It is even possible that the migrant, after a period of unemployment returns to work and then leaves the country. The transition probability takes all the possible transitions into account. Dabrowska et al. (1994) describe how we can derive these transition probabilities for the semi-Markov model we use.

The transition probability from state $j$ to state $k$ after a duration $t$ (time since the migrant entered the host for the first time) is formed by adding all possible intermediate transitions that start in $j$ and end in $k$ at time $t$. First consider the migrants who do not make a transition in $(0, t)$, thus $j=k$. Those individuals remain in $j$ till $t$, say the employed migrants who remain working. The probability that the employed remain working is equal to the total survival of the employed, $S_{j}(t)$. Next we have the migrants who make one transition within a period $t$ since they entered the country, say from employment to non-participation, and then remain in this state till the end of the period. The probability that a transition from $j$ to $k$ before $t$ occurs and the migrants then remain in $k$ is equal to

$$
\int_{0}^{t} f_{j k}(u \mid \cdot) \cdot S_{k}(t-u) d u
$$

with $f_{j k}(t)=\partial F_{j k}(t) / \partial t$, the 'subdistribution density'. Some migrants may after first first making a transition from employment to non-participation end abroad. The probability to make a transition from $j$ to $k$ within a period $t$ with one intermediate initial transition is

$$
F_{j k}^{(2)}(t \mid \cdot)=\int_{0}^{t} \sum_{m=1}^{4} F_{j m}(u \mid \cdot) \cdot f_{m k}(t-u \mid \cdot) d u
$$

with the cumulative incidence from $j$ to $j, F_{j j}(t \mid \cdot)=0$. Then, the probability that a migrant who made these two transitions and who remains in state $k$ till $t$ is

$$
\int_{0}^{t} f_{j k}^{(2)}(u \mid \cdot) S_{k}(t-u) d u
$$

with $f_{j k}^{(2)}(u \mid \cdot)=\partial F_{j k}^{(2)}(t) / \partial t$. This reasoning is repeated for any number of intermediate transitions from state $j$ to state $k$ Thus, the transition probability, that is the probability to be in $k$ starting in $j$ after a duration $t$ is

$$
P_{j k}(t \mid \cdot)=S_{j}(t \mid \cdot) \cdot I(j=k)+\sum_{p \geq 1} \int_{0}^{t} f_{j k}^{(p)}(u \mid \cdot) S_{k}(t-u) d u
$$

where $f_{j k}^{(p)}(t)=\partial F_{j k}^{(p)}(t) / \partial t$ and

$$
F_{j k}^{(p)}(t \mid \cdot)=\int_{0}^{t} \sum_{m=1}^{4} F_{j m}^{(p-1)}(u \mid \cdot) \cdot f_{m k}(t-u \mid \cdot) d u
$$


In our data we follow labour immigrants to The Netherlands who are employed at entry. We follow the labour market and migration dynamics of these labour migrants. Thus, we are only interested in the transition probability from employment, $P_{1 k}(t \mid \cdot)$. After estimating all the competing risks models for all the possible transitions we will derive the path of these transition probabilities for the reference individual and discuss the impact of observed characteristics on these probabilities.

Again no direct relation between the coefficients of the competing risks models and the effect of the covariates on the transition probability exists. We therefore calculate the (discrete) marginal effects of the migrant characteristics on these transition probabilities, with the reference migrant.

\section{Data on immigrants to The Netherlands}

In the early 1960s The Netherlands changed from an emigrant to an immigrant country. Immigration follows a European sequence of post World War II and post-colonial immigration, unskilled manpower recruitment and the arrival of refugees. The first period is characterized by the de-colonization of Indonesia in 1949, as a consequence many Indonesian people came to The Netherlands. In the second period, starting in the beginning of the 1960s, a large flow of 'guestworkers', mainly Turks and Moroccans arrived. The Dutch government regulated the recruitment practices by bilateral agreements with the main countries. The total inflow of immigrants reached 235,000 in 1970s. The recruitment policy stopped during the first oil crisis. However, the immigration from the recruitment countries continued as a follow-up migration, first in the form of family reunification and later also family formation. In this period the independence of Surinam also caused large immigration. Starting in the 1980s, immigration is characterized by the family reunification/formation of 'guestworkers'. Additionally, the flow of political refugees, asylum seekers has increased dramatically. In the political discourse it is often forgotten that the number of labour immigrants from neighbouring countries and other EU countries has always been substantial. In the last twenty years the majority of labour immigrants come from these countries or from other western countries. The forming of the European Union and the EU treaty of 1993 that allows free movement of people within the union has facilitated the migration within the EU. In 2004 the EU was enlarged with 10 more countries. ${ }^{4}$ However, only in May 2007 people from these new EU countries received full access to the Dutch labour market. The Dutch government recognized in 2004, in light of the Lisbon agreement, the need for high skilled migrants to sustain further economic growth. This 'knowledge regulation' simplifies entry into The Netherlands

\footnotetext{
${ }^{4}$ The enlargement in 2007 with 5 more countries is beyond the observation period of our database.
} 
for migrants who will earn more than $€ 47$ thousand a year. ${ }^{5}$

The annual emigration from The Netherlands was rather stable between the late 50s till the late 80s. In those years around 60 thousand people left the country each year. In the early 50s emigration peaked at 80 thousand people. This was mainly due to active emigration policies of the Dutch government. These active emigration policies were inverted into an active immigration policy in the 60 s when a shortage of labour occurred. In the 90s and early this century emigration increased fast, to reach a new peak at 132 thousand emigrants. However, the composition of the recent emigrants differs substantially from the composition of the emigrants in the 50 s and 60 s. In the latter period the emigrants were almost entirely native Dutch, while two-thirds of the recent emigrants are non-native, see Nicolaas (2006). Recent research have shown that many migrants leave fast, within five years $40 \%$ of the recent migrants have left the country, and that migration experience accelerates this process (Zorlu et al. (2004), van Gaalen et al. (2008) and Bijwaard (2010)).

We have data on recent immigration and emigration to and from The Netherlands (1999-2005). All immigration by non-Dutch citizens, immigrants who do not hold the Dutch nationality, who legally entered The Netherlands is registered in the Central Register Foreigners (Centraal Register Vreemdelingen, CRV), using information from the Immigration Police (Vreemdelingen Politie) and the Immigration and Naturalization Service (Immigratie- en Naturalisatie Dienst, IND). ${ }^{6}$ For all these immigrants without the Dutch nationality we know when their migration move(s) took place and what their migration motive was to enter the Netherlands. For people with a nationality that implies a visa to enter The Netherlands, their migration motive can be directly derived from their legal entry status. People with other, Western nationalities, fill in their migration motive at their mandatory registration at their municipality of residence. With these data we can identify important groups of immigrants to the Netherlands. Statistics Netherlands make the distinction between labour-migrants, family reunification migrants, family-formation migrants, student immigrants, asylum seekers (and refugees), and immigrants for other reasons (including a.o. joining with labor migrant, medical treatment and Au Pair). Of course, the official migration motive does not always match with the true intention of the migrants. Some refugees and family migrants have, partially, economic motives to enter the country. Still the labour participation of these migrants is substantially lower than for labour migrants, see Sprangers et al. (2004). We focus on migrants with a labour motive and who are employed in The

\footnotetext{
${ }^{5}$ See Zorlu and Hartog (2002) and Van Ours and Veenman (2005) for a more detailed discussion on the immigration to The Netherlands.

${ }^{6}$ The criterion for registration as an immigrant in the Netherlands is a four months time criterion. To be more precise: every person intending to stay in the Netherlands for at least two thirds of the forthcoming six months, should notify the local population register immediately after the arrival in the Netherlands.
} 
Netherlands within three months of their entry.

The CBS, Statistics Netherlands, has linked these data to the Municipal Register of Population (Gemeentelijke Basisadministratie, GBA) and to their Social Statistical database (SSB). The GBA data contain basic demographic characteristics of the migrants, such as age, gender, marital status and country of origin. From the SSB we have information (on a monthly basis) on the labour market position, income, industry sector and household situation. The most important income source determines the labour market position. Based on the income source CBS distinguishes nine labour market categories: employed, self-employed, unemployment benefits, disability benefits, social security benefits, other benefits, pensions, students and non-participating (no income). We combine the first two categories to an employed status. All the other categories except for the last are combined to the unemployment, receiving benefits, category. Note that many recent non-EU immigrants are not eligible for most benefits in The Netherlands. They can only draw on these benefits after some years of employment/residence in the country. Because we are interested in the labour market behaviour of migrants we restrict our analysis to the (non-Dutch) labour migrants immigrants. We further restrict our sample to the immigrants between 18 and 64 years of age. About $23 \%$ of all non-Dutch immigrants in these age brackets are labour migrants. The same data was used by van Gaalen and Bijwaard (2008) to analyse return migration of this group of migrants. Here we extend the analysis to include labour market dynamics on the Dutch labour market.

\section{Put Table 1 about here}

In Table 1 we present some descriptive statistics for the data and compare the averages with the averages for the Dutch workforce. Labour migrants are mostly men, even more than the Dutch workforce. They are more often single and less often married or have children at home. The immigrants are relatively young. They work more often in services and as temporary workers. The migrants also work relatively often in education. The table also shows the distribution of the migrants over a selected group of countries/regions of origin. ${ }^{7}$ The majority of labour migrants originates from a country in the European Union, in particular from the neighbouring countries UK, Germany, France and Belgium.

\section{Put Table 2 about here}

\footnotetext{
${ }^{7}$ EU15/EFTA are countries in the European Union, except for the 2004 new members and except for Belgium, Germany, UK and France plus the member countries of EFTA: Switzerland, Norway, Iceland. Former Yugoslavia are Croatia, Serbia \& Montenegro, Macedonia and Bosnia. New EU members are the countries that joined the European Union in 2004: Cyprus, Czech Republic, Estonia, Hungary, Latvia, Lithuania, Malta, Poland, Slovenia and, Slovakia.
} 
The migrants in our sample show a substantial dynamic behaviour. Of all the migrants that enter, including those that arrive in December 2003, $48 \%$ leaves the country at least once, $24 \%$ has more than one employment spell, $11 \%$ has at least one unemployment spell and $40 \%$ has at least one non-participation spell. Table 2 report the observed transitions among the four different states. The majority of employment spells end in non-participation, while the majority of non-participation spells end abroad. The majority of the spells abroad are censored, the migrants are still abroad at the end of the observation period. Close to half of the relatively small number of unemployment spells end in employment. But a third of the unemployed leave the labour market. Very few migrants leave the country from unemployment.

\section{Put Figure 1 about here}

By definition any labour migrant starts in the employed state at entry. Soon after arrival some migrants move to the other states. Some may return and some may move on to another state. But the migrant is always in one of the four states. In Figure 1 we depict the development of the distribution over the four states for the 1999-entry cohort. The most prominent feature of this development is that only a few migrants get unemployment benefits. Thus, the financial burden on the Dutch economy of these migrants is small. Instead, a substantial proportion of the migrants become nonparticipating (without receiving benefits), possibly because they do not have gained any benefit rights in the Netherlands. The proportion of migrants abroad continuously increases. Six years after arrival more than $50 \%$ of the labour migrants have left the country. When we combine this result with the numbers in Table 2 it seems that non-participation is a temporary status before the migrant leaves the country.

\section{$5 \quad$ Empirical Findings}

For each of the four labour market status separately we estimate competing risks models to the other destination states. We assume a piecewise constant baseline intensity on eleven intervals (every six months and beyond five years) and a two-point discrete unobserved heterogeneity. The covariates included (see Table 3) in the model refer to demographic (gender, age, martial status and age of children), country of origin, and individual labour market characteristics (monthly income, industry sector). Labour market history and migration history is also included. For transitions from employment we include a dummy for previous employment experience. For transitions from unemployment and from non-participation we include a dummy for previous unemployment and for non-participation 
experience. For all transitions from the Dutch labour market we include a dummy for repeated immigration to the Netherlands. For transitions back to the Netherlands we include the labour market status at departure and a dummy for repeated emigration.

We control for business cycle conditions by including the national unemployment rate, both at the moment of first entry to the country and the time-varying monthly rate. The unemployment rate at entry captures the 'scarring effect' of migrants, while the running unemployment rate captures the impact of the business cycle on the transition intensities.

For transition from employment the reference individual is a 30-35 year old single male without children from a EU/EFTA-country (except the neighboring countries UK, Belgium, France or Germany) employed in the trade sector and with a monthly income of $€ 2000-€ 3000$. For both the unemployed and the non-participating the industry sector is dropped from the analysis. A non-participating migrant has, by definition, no income. Thus income is not included in the transition intensities from non-participation. The reference national unemployment rate is the average registered unemployment rate in the Netherlands for the period 1999-2005 which was $3.1 \%$.

\subsection{One step ahead analyses}

We used maximum likelihood estimation to obtain the estimated parameters for all transition intensities. For the estimation we use the likelihood in (3) with a two-point discrete unobserved heterogeneity distribution. From the estimated coefficients we first derive the total survival and cumulative incidence rates for the reference migrant from each state, see Figure $2{ }^{8}$ From employment the majority of transitions is to non-participation. After five years about $40 \%$ of the employed labour migrants has left the labour market and $6 \%$ has left the country. The departure from unemployment, depicted in the upper-right corner of the picture, is very fast. Within two years most unemployed individuals have left unemployment. A large majority of the unemployed become employed again (70\%). However, a substantial proportion, 20\%, leaves the labour market and becomes non-participating. A large proportion of the non-participants leaves the country. Five years after becoming a non-participant about $40 \%$ of the migrants has left the country. But, we also find that $45 \%$ of them return to work within five years. Combining the two left-hand side picture we see that departure of labour migrants from the Netherlands is driven by migrants that first become non-participants and then leave the country.

\section{Put Figure 2 about here}

\footnotetext{
${ }^{8} \mathrm{~A}$ full list estimates is available from the author upon request.
} 
As discussed in Section 3.1 the interpretation of the coefficients in a competing risks model is not straightforward, because the probability to exit to a particular state not only depends on the intensity to leave to this state but also on the intensities to leave to the other states. In Table 4 till Table 7 the marginal effects on the exit probability, the limit of the cumulative incidence, of selected covariates are presented. Presenting the marginal effects for all covariates (see Table 3) for all four origin states would result in many more tables. We choose to report only those variables for which at least one of the marginal effects is significant (on a $5 \%$ level). Note that only a few countries of origin play a significant role in explaining the differences in exit probabilities.

The discussion of these marginal effects is included in the discussion of the transition probabilities in the next Section. One issue hidden in the analysis of the transition probabilities is, however, the impact of migration and labour market experience on the dynamics. Employed migrants who have been abroad are very likely to leave the country again, see DaVanzo (1983). A disrupted employment spell increases the chance to leave to unemployment and the chance of going abroad. Repeated unemployment spells increases the chance to exit unemployment to employment. However, it decreases the chance to exit from non-participation to employment or abroad. (Repeated) non-participation experience decreases the probability to exit from unemployment to employment dramatically, but has less impact on the exit probability from non-participation. Migrants who leave the country form unemployment or nonparticipation have a smaller chance enter the country again in employment. The first enter the country more often unemployed and the second enter more often without income.

\subsection{Transition probabilities}

The total survival, cumulative incidence function and exit probability only look one event ahead. To get the complete picture of the labour market dynamics of migrants we calculate the transition probability, using the approach mentioned in Section 3.2. The transition probability takes all possible transitions among the four states into account. Since the migrants are, by definition, all employed at arrival, we only calculate the transition probability from employment. The transition probability then provides the distribution of the migrants over the four states as a function of the time since they

first arrived in the Netherlands. Figure 3 depicts this distribution, together with the $95 \%$ confidence intervals, for a reference migrant (see page 16) up to ten years after the first arrival.

\section{Put Figure 3 about here}

The percentage of the migrants that is employed decreases with the time since arrival, but not as fast as the survival rate in employment in Figure 2. This figure also shows that many migrants 
return from non-participation to employment. This inflow increases the employment rate of the migrants. Departure from the country is much higher than the cumulative incidence from employment to abroad as depicted in Figure 2. Again this is caused by the transition from non-participation. The percentage of migrants without income stabilizes after three years at around $10 \%$. We also note that unemployment among the labour migrants is very low (1.6\% after 10 years in the country). Thus, the financial burden of the labour migrants on the Dutch economy seems very low. However, even if at one particular point in time the number of unemployed migrants may be low many more migrants may have been unemployed during their stay. Many migrant are only unemployed for a short period of time. This is hidden in the transition probability. In the next section we discuss how we can derive how often and for how long migrants get unemployed (and many more relevant indicators) using microsimulation.

Five years after arrival $75 \%$ of the reference migrants (see page 16) is still employed, $11 \%$ is nonparticipating, $14 \%$ is living abroad and only $1 \%$ is unemployed. Again no direct relation between the coefficients of the competing risks models and the effect on the transition probability exists. We therefore calculate the (discrete) marginal effects on the transition probability. Table 8, together with Figure 4 to Figure 6, reports these marginal effects on the transition probability five years after the first arrival to the Netherlands (only for selected covariates).

First we focus on the personal characteristics of the migrants. Gender is relatively unimportant. Women have a slightly higher chance to become unemployed and a slightly lower chance to leave the country (see also Table 4-7 ). Married, cohabiting and divorced migrants have a higher probability to remain employed (compared to the single, never married, migrant) and a lower probability to leave the country. For cohabiting and divorced migrants the latter is mainly caused by the exit rates from nonparticipation, high to employment and low to another country (see also Table 6). Older migrants have, just as older natives, a lower chance to remain employed and a higher chance to become unemployed. They have a higher chance to become unemployed and a lower chance to return from unemployment back to employment. Children in the household of the migrant lead to slightly higher chance to remain employed and a lower chance to have no income. For these households a period without income is hard to endure.

Self-employed migrants have a higher probability to stay in the country and to remain employed. Five years after entry $90 \%$ is still employed. Self-employment implies a risky investment which increases the ties to the country. It seems that those migrants are rather good in setting up a new business. The impact of income on the employment probability is U-shaped. Both low and high 
income migrants have a lower probability to remain employed. For low income migrants only half of them is still employed in the Netherlands five years after arrival and about $20 \%$ has left the country. These figures hardly change when we look at longer times sice arrival (see Figure 4 and 6). Low income migrants also become unemployed and non-participating relatively often. High income migrants leave the country even faster ( $30 \%$ within 5 years). However, they enter unemployment less often. The reason for low income migrants to have a low employment probability is mainly because they have low job security. Some of them leave the country to try their luck elsewhere. For high income migrants a competitive international labour market exists. So, they leave for another country if they can earn more there.

The sector the (employed) migrant is working in has a large impact on the dynamics. Many migrants work in the temporary work sector. They have a limited contract length and therefore they leave the country fast. Again the route out of the country is very often via non-participation. This is also the reason that migrants working in the catering industry and agriculture leave the country faster. The better labour market prospects of the highly educated migrants working in the education sector is reflected in a lower non-participation rate.

The labour market behaviour of the migrants also depends on the country of origin. We would expect that migrants from Western countries have stronger ties to the Dutch labour market. Our estimated marginal effects of the exit probability do not completely support this hypothesis. This holds for migrants from neighbouring Belgium and Germany, but migrants from the other neighbouring countries, the UK and France, seems to behave differently. They have worse labour market prospects. A possible explanation is that people from Belgium share the Dutch language and German is also closer to Dutch than English and French. Migrants from Japan and North-America leave faster. Many expatriates working for multinationals come from these countries. These workers often have a fixed term contracts in one particular country. This is in particular visible for the Japanese labour migrants as their probability to remain employed is higher the first two years after arrival (see Figure 4). Migrants from the new EU-countries have good prospects on the Dutch labour market. They are more often repetitive migrants (see Table 7). The migrants from the old guest-worker countries, Morocco and Turkey, show different dynamics. Turkish migrants have low attachment to the labour market and leave more often, while Moroccan migrants become unemployed more often and leave less often. Note that nowadays only a small number of the labour migrants arrive from these countries.

The business cycle at the moment of arrival has little effect on the employment rate of migrants. The unemployment rate during their stay has the expected impact. When the unemployment rate is 
high migrants work less, are more often unemployed and leave the country more often.

\section{Scenario analyses}

The transition probabilities give the probability that a labour migrant is in any of the states after a given time since the migrant entered the country. They take the full dynamics into account. However, we loose the information on how an individual reached a certain state. From the total survival and cumulative incidence functions we could predict the (average) time the migrant has spent in the intermediate states until he reaches the final state. Still, many relevant indicators of the paths of the immigrants on the host labour market cannot be derived analytically. For example, the average number of unemployment spells and the average length of each unemployment spell are impossible to deduce directly from the transition probability or from the estimated parameters. In this section we provide these, and many more, indicators on the basis of simulations. These simulations use the estimated parameters of the multi-state multiple spell competing risks model and the observed entry into the The Netherlands as input.

First we simulate a base scenario. This base scenario is based on a synthetic cohort of labour migrants, all entering at the same time. The synthetic cohort consists of 50000 migrants, for which the distribution of the start population of migrants equals the observed entry distribution. For each simulation round we draw a vector of parameter estimates assuming that the estimated coefficients are normally distributed around the point estimates with a variance-covariance matrix equal to the estimated one. Then, on a monthly basis, we simulate the transitions for each member of the synthetic cohort using the implied transition intensities. If the simulated migrant becomes unemployed we use the transition intensity from unemployment, and similar for a non-participating migrant and a migrant abroad. We use the evolution of the labour-migration path, the history of all occurrences of labour market and migration states, of each individual member in the (dynamic) simulation. Thus, if a (simulated) migrant enters the Dutch labour market again we take the effect of repeated entry (and possible labour market experience) into account. We simulate the labour-migration path for ten years and in the end we save the whole simulated migrant history. We repeat the simulations 100 times.

Table ?? reports the obtained indicators of this base scenario. A labour migrant, ten years after arrival, has spent more than half of this time employed and three and a half a month unemployed. The migrant has more than two employment spells each lasting almost 3 years. Unemployment spells last on average six months, non-participation spells last almost a year and the periods abroad almost four years. If a migrant has been unemployed at least once it has on average almost two spells. Thus, 
previous unemployment almost doubles the chance to become unemployed. A previous period without income in The Netherlands more than doubles the chance to experience it again. Emigration experience also increases the migration dynamics. Thus, for each of these transitions earlier experiences increase the chance of reoccurrence.

The situation ten years after entry could also be derived from the transition probability. The simulations provide the situation for the observed characteristics distribution of the immigrants, which could be obtained from the transition probability by integrating out this distribution. Ten years after entry $50 \%$ of the migrants are 'still' employed, $4 \%$ are unemployed, $13 \%$ are non-participating and $32 \%$ are abroad. Looking at these numbers unemployment of migrants only seems a minor issue. However, only $17 \%$ of the migrants remain employed for the whole ten years. Within ten years $30 \%$ of the migrants ever become unemployed. Some of these unemployment spells are rather short. Still, $16 \%$ of the migrants experiences an unemployment spell longer than six months, $9 \%$ experiences an unemployment spell longer than one year and $5 \%$ experiences an unemployment spell longer than two years.

The labour migrants spend a considerable amount of time in the country without income. More than $\frac{2}{3}$ of the migrants ever experiences such a period of non-participation. These periods of no-income can be rather long as more than $50 \%$ of the migrants has such periods for longer than six months. A quarter of the migrants has no-income periods of more than two years. The majority of migrants that leave the country remain abroad. More than $40 \%$ ever leaves and $37 \%$ stays abroad for more than one year.

Another way to analyse the labour market dynamics of the migrants is to look at the most common paths of the migrants on the labour market. The first column of Table 11 present the frequency distribution of the paths of the simulated migrants. The first column of Table 12 presents the average duration spent in each state for the eleven most common paths. The five most common paths are depicted in the left-upper corner of Figure 8. The most common path (17\%) of the labour migrants is that they remain employed for the whole ten years. Around $8 \%$ of the migrants interrupt their employment with $1 \frac{1}{2}$ year without income. Another $8 \%$ leaves the country after, on average, 3 years in the country. Many of the labour market paths of the migrants involve some period without income, after which the migrants either return to work or leave the country. The reason why so many migrants go through the non-participation state is that most migrants are not (yet) eligible for unemployment benefits. Why they stay in the country without income is unclear. They might have enough wealth to survive a period without income. Or, they might have relatives in the country who support 
them. A final reason to remain in the country without income is that they have income from abroad. Unfortunately, the data do not provide us information to distinguish among these causes.

Simulations can also provide scenario analyses. We consider three alternative scenario's. From a policy perspective it is very important to know what would happen with the labour market dynamics of new immigrants when the unemployment rate increases rapidly, as is currently encountered due to the Credit Crunch. In our first scenario (UNEMPLOYMENT) we simulate the effect of an increase from the current average unemployment rate in The Netherlands of $3.1 \%$ to $6 \%$ on the labour market and migration dynamics of new immigrants. The second scenario (NEW EU) looks at the recent huge, but only partly captured by the data, inflow of immigrants from the EU accession countries, the countries that joint the EU in 2004. From 2002 to 2007 their number quadrupled. The third scenario (HIGH INCOME) considers the effect of a recent policy to moderate the immigration of immigrants with a high income. We assume that this leads to a $50 \%$ increase in the inflow of high income immigrants and simulate the impact of this increase on the labour market and migration dynamics of all immigrants.

For the unemployment scenario we use, just as in the base scenario, the entry distribution to construct this cohort. For the new EU and the high income scenario we adjust the entry distribution. For the new EU scenario the number of immigrants form the EU accession countries is quadrupled and for the high income scenario the number of immigrants with an income above $€ 5000$ per month is increased by $50 \%$. Table 10 to table 12 report the result of these simulations. In Figure 7 to Figure 8 the transition probabilities of each of the scenario's are reported.

It is not surprising that the time migrants spent in unemployment increases when the unemployment rate in The Netherlands increases. However, the probability that a migrant experiences at least one unemployment spell does not increase. The probability on repeated unemployment even decreases significantly. When the national unemployment rate would increase the average length of the unemployment spell of migrants increases with more than $60 \%$. It also induces more migrants to leave the country, but they also return from abroad more often. The probability to become non-participating in the country declines and the average duration of such a period without income increases. Although the time spent employed and the probability to be employed ten years after entry both decrease the fraction of migrants that remains employed for the whole ten year period increases. Thus, the deterioration of the labour market induces the unsuccessful migrants to search for other jobs abroad.

When the inflow of migrants from the EU accession countries, especially Poland, quadruples, the time spent in employment increases and the time spent in unemployment decreases. This also leads to more, but shorter, employment spells and periods abroad. This is in line with the large number 
of seasonal workers from these countries. Unemployment spells become less frequent and shorter. This leads to a substantial decline in the percentage of migrants that ever get unemployed. We can therefore conclude that we expect that those migrants will fare relatively well on the Dutch labour market.

When the policy of attracting more high income migrants to The Netherlands is really successful, the long run effects on the labour market are small. Although the time in unemployment and nonparticipation of migrants decreases, the time in employment will also decrease. More migrants leave the country and they will stay abroad longer. Many high income migrants are expatriates who have a temporary contract. Those migrants perceive their stay in The Netherlands as a temporary phase in their career.

\section{Conclusion}

Most previous studies have focused primarily on earnings, with little attention on the issue of labour market status. The importance of repeat and circular migration is also largely overlooked. In this paper a coherent modeling approach is developed to model the interrelation of labour market transitions and out- and repeat migration of immigrants. To this end we estimate a multi-state multiple spell competing risks model and identify four states: employed, unemployed receiving benefits, nonparticipating (out-of-the-labour market, and no benefits) and abroad. The first three states indicate the labour market status of the immigrant in the host country.

For the analysis we use data on recent labour immigrants to The Netherlands, which implies that all migrants are (self)-employed at the time of arrival. The data further contain information on the timing of migration moves, timing of labour status, income change and employment sector. We also have demographic information, such as the country of origin and marital status. We show that many migrants leave the country after a period without income.

We show that personal characteristics (gender and marital status), employment characteristics (self-employment, income and sector) and country of origin play an important role in explaining the labour market dynamics of the migrants. A migrant who has gained knowledge about the Dutch labour market through multiple entry has a higher probability to remain employed. Both low and high income migrants have a lower probability to remain employed. The low income migrants also become non-participating relatively often. High income migrants also leave the country fast. However, they do not enter non-participation more often.

To obtain more insight in the labour market and migration paths of the labour migrants, that 
cannot be derived analytically, we simulated the dynamic behaviour of a synthetic cohort of 50,000 of these migrants. First, we simulated the paths of the current inflow of migrants, the base scenario, by using the observed entry distribution as start population. From this microsimulation we reveal that although after ten years only a small percentage of the migrants is unemployed, almost one-third experiences an unemployment spell within ten years of arrival. Thus, at first sight it seems that only a very limited number of the labour migrants draw on the Dutch social security system, while the results from microsimulation indicate that $9 \%$ of the migrants have unemployment spells of more than one year.

Microsimulation also provides a framework to conduct scenario analysis. We considered three alternative scenario's. Our first scenario tried to mimic the foreseen increase in the national unemployment rate due to the current Credit Crunch. Not surprisingly, an increase in the national unemployment rate increases the unemployment rate of the migrants. However, this is mainly caused by longer unemployment spells of those who get unemployed, and hardly by an increase in the number of migrants that ever become unemployed. It also induces more migrants to leave. But, it also leads to more migrants that remain employed.

The second scenario mimics the recent acceleration of the inflow of migrants from the countries that joined the EU in 2004. A quadrupling of those migrants leads to better labour market perspectives for the migrants (on average). Migrants from these countries are often seasonal workers, which is reflected in their more frequent, but shorter, employment spells. The third scenario assumes that the recent entry simplification of high income migrants would lead to an increase of the inflow of these migrants by $50 \%$. This will not have a lasting impact as many of these high income migrants leave the country fast.

Very often a period without income proceeds the departure from the country. It seems odd that so many migrants stay, for relatively long periods, in The Netherlands without income. The reason is that many of these recent migrants are not (yet) eligible for unemployment benefits. But the question is how these migrants can survive without income. Three possible explanations are that $(i)$ those migrants have enough wealth to survive a period without income, $(i i)$ they have relatives in the country who support them, or (iii) they have income from abroad. Unfortunately, the data do not provide us information to distinguish among these causes. An avenue for further research is therefore to investigate this in more detail. 


\section{References}

Bailey, A. J. (1993). Migration history, migration behavior and selectivity. The Annals of Regional Science 27, 315-326.

Berninghaus, W. and H. Seifert-Vogt (1988). Temporary versus permanent migration: A decision theoretical approach. Journal of Population Economics 1, 195-211.

Bijwaard, G. E. (2010). Immigrant migration dynamics model for The Netherlands. Journal of Population Economics 54, forthcoming.

Borjas, G. J. (1999). The economic analysis of immigration. In O. Ashenfelter and D. Card (Eds.), Handbook of Labor Economics, Volume 3A, Chapter 28. Amsterdam: North-Holland.

Borjas, G. J. and B. Bratsberg (1996). Who leaves? The outmigration of the foreignborn. The Review of Economics and Statistics 78, 165-176.

Borjas, G. J. and L. Hilton (1996). Immigrantion and the welfare state: Immigrant participation in means-tested entitlement programs. Quarterly Journal of Economics 111, 575-604.

Cameron, A. C. and P. K. Trivedi (2005). Microeconometrics: Methods and Applications. Cambridge University Press.

Chiswick, B. R. (1978). The effect of Americanization on the earnings of foreign-born men. Journal of Political Economy 86, 897-921.

Chiswick, B. R., Y. Cohen, and T. Zach (1997). The labor market status of immigrants: Effects of the unemployment rate at arrival and duration of residence. Industrial $\&$ Labor Relations Review 50, 289-303.

Constant, A. and D. S. Massey (2003). Self-selection, earnings and out-migration: A longitudinal study of immigrants to Germany. Journal of Population Economics 16, 631-653.

Constant, A. and K. F. Zimmermann (2003). Circular movements and time away from the host country. Discussion Paper 960, IZA, Bonn.

Dabrowska, D. M., G. Wen, and M. M. Horowitz (1994). Cox regression in a Markov Renewal model: An applocation to the analysis of bone marrow transplant data. Journal of the American Statistical Association 89, 867-877.

DaVanzo, J. (1983). Repeat migration in the United States: Who moves back and who moves on. The Review of Economics and Statistics 65, 552-559. 
Detang-Dessendre, C. and I. Molho (1999). Migration and changing employment status: A hazard function analysis. Journal of Regional Science 39, 103-123.

Dustmann, C. (1995). Return migration: The European experience. Economic Policy 22, 214-250.

Dustmann, C. and Y. Weiss (2007). Return migration: Theory and empirical evidence. British Journal of Industrial Relations 45, 236-256.

Hansen, J. and M. Lofstrom (2003). Immigrant assimilation and welfare participation: Do immigrants assimilate into or out-of welfare. Journal of Human Resources 38, 74-98.

Hansen, J. and M. Lofstrom (2009). The dynamics of immigrant welfare and labor market behavior. Journal of Population Economics 22, 941-970.

Hill, J. K. (1987). Immigrant decisions concerning durations of stay and migratory frequency. Journal of Development Economics 25, 221-234.

Jasso, G. and M. R. Rosenzweig (1982). Estimating the emigration rates of legal immigrants using administrative and survey data: The 1971 cohort of immigrants to the us. Demography 19, 279-290.

Kirdar, M. G. (2008). Estimating the impact of immigrants on the host country social security system when return migration is an endogenous choice. Discussion Paper 7803, MPRA, Munich.

Kirdar, M. G. (2009). Labor market outcomes, savings accumulation and, return migration. Labour Economics 16, 418-428.

Kyyrä, T. (2009). Marginal effects for competing risks models with piecewise constant hazards. Oxford Bulletin of Economics and Statistics 71, 539-565.

Long, L. C., J. Tucker, and W. L. Urton (1988). Migration distances: An international comparison. Demography 25, 633-660.

Longva, P. (2001). Out-migration of immigrants: Implications for assimilation analysis. Memorandum 04/2001, University of Oslo.

Massey, D. S., J. Arango, G. Hugo, A. Kouaouci, A. Pellegrino, and J. E. Taylor (1993). Theories of international migration: A review and appraisal. Population and Development Review 19, $431-466$.

Nicolaas, H. (2006). Nederland: Van immigratie- naar emigratieland? (The Netherlands: From immigration- to emigration country?). Bevolkingstrends 54, 33-40. 
Sprangers, A., A. Zorlu, J. Hartog, and H. Nicolaas (2004). Immigranten op de arbeidsmarkt (Immigrants on the labour market). Sociaaleconomische trends 2004, 27-37.

Stark, O. (1991). The Migration of Labor. Cambridge: Basil Blackwell.

Storesletten, K. (2000). Sustaining fiscal policy through immigration. Journal of Political Economy 108, 300-323.

Thomas, J. M. (1996). On the interpretation of covariate estimates in independent competing risks models. Bulletin of Economic Research 48, 27-39.

Uhlendorff, A. and K. F. Zimmermann (2006). Unemployment dynamics among migrants and natives. Discussion Paper 2299, IZA, Bonn.

van Gaalen, R. and G. E. Bijwaard (2008). Wat bindt arbeidsmigranten aan Nederland? Levensloopdynamiek van tussen 1999 en 2003 gearriveerde arbeidsmigranten (What binds labour migrants to The Netherlands? Life cycle dynamics of labour migrants who arrived between 1999 and 2003). In M. Mols, H. J. Dirven, and R. van der Bie (Eds.), Dynamiek in de sociale statistiek: Nieuwe cijfers over de sociaaleconomische levensloop, pp. 191-205. The Hague: CBS.

van Gaalen, R., J. Ooijevaar, and G. E. Bijwaard (2008). Eerder verblijf in Nederland vergroot kans op vertrek én terugkomst (Previous stay in the Netherlands enlarges the chance to return and repeated migration). Bevolkingstrends 56, 39-43.

Van Ours, J. and J. Veenman (2005). The netherlands; old emigrants - young immigrant country. In K. Zimmermann (Ed.), European Migration: What do we know?, pp. 173-196. Oxford UP.

Waldorf, B. S. and A. Esparza (1991). A parametric failure time model of international migration. Papers in Regional Science 70, 419-438.

Zorlu, A. and J. Hartog (2002). Migration and immigrants: The case of The Netherlands. In R. Rotte and P. Stein (Eds.), Migration Policy and the Economy: International experiences, pp. 119-140. München: Hans Seidel Stiftung.

Zorlu, A., J. Hartog, A. Sprangers, and H. Nicolaas (2004). Retourmigratiegedrag van recente immigranten (Return migration of recent immigrants). Economische Statistische Berichten (ESB) August 20, 2004, 402-404. 
Table 1: Descriptive statistics (sample mean at arrival)

\begin{tabular}{|c|c|c|}
\hline & immigrants & " total workforce (2000) \\
\hline average age & 32 & 38 \\
\hline aged $18-25$ & $19 \%$ & \\
\hline aged $50-55$ & $3 \%$ & \\
\hline aged $55-60$ & $1 \%$ & \\
\hline female & $29 \%$ & $41 \%$ \\
\hline married & $24 \%$ & $60 \%$ \\
\hline Divorced & $2 \%$ & $8 \%$ \\
\hline single, no kids & $47 \%$ & $20 \%$ \\
\hline Children at home & $15 \%$ & $49 \%$ \\
\hline \multicolumn{3}{|c|}{ Social Economic variables } \\
\hline Av. monthly income & $€ 3003$ & \\
\hline Income $<1000$ & $19 \%$ & $7 \%$ \\
\hline Income $1000-2000$ & $32 \%$ & \\
\hline Income $2000-3000$ & $19 \%$ & \\
\hline Income $3000-4000$ & $8 \%$ & \\
\hline Income $4000-5000$ & $4 \%$ & \\
\hline Income $>5000$ & $15 \%$ & $22 \%$ \\
\hline Working in industry & $11 \%$ & $14 \%$ \\
\hline Working in trade & $14 \%$ & $17 \%$ \\
\hline Working for temporary offices & $14 \%$ & $3 \%$ \\
\hline Working in services & $24 \%$ & $16 \%$ \\
\hline Working in education & $7 \%$ & $6 \%$ \\
\hline Working in catering & $6 \%$ & $4 \%$ \\
\hline Working in transportation & $6 \%$ & $7 \%$ \\
\hline \multicolumn{3}{|c|}{ Country of origin } \\
\hline Belgium & $5 \%$ & - \\
\hline Germany & $10 \%$ & - \\
\hline UK & $18 \%$ & - \\
\hline France & $6 \%$ & - \\
\hline rest EU15/EFTA & $23 \%$ & - \\
\hline new EU & $5 \%$ & - \\
\hline North-America & $6 \%$ & - \\
\hline Japan & $3 \%$ & - \\
\hline Australasia/Asia & $13 \%$ & - \\
\hline Africa & $5 \%$ & - \\
\hline Turkey & $2 \%$ & - \\
\hline Morocco & $1 \%$ & - \\
\hline \# observations & 54832 & $7,2 \mathrm{mln}$ \\
\hline
\end{tabular}

Source: Statistics Netherlands, based on own calculations. 
Table 2: Spell dynamics of the labour migrants (\# 45,987)

\begin{tabular}{l|r|rrrr}
\hline \hline & & \multicolumn{4}{|c}{ Percentage ending in } \\
& \# of spells & employed & UI & NP & Abroad \\
\hline Employed & 73375 & $43 \%$ & $6 \%$ & $39 \%$ & $12 \%$ \\
Unemployed (UI) & 8735 & $46 \%$ & $22 \%$ & $28 \%$ & $4 \%$ \\
Non-participation (NP) & 31873 & $44 \%$ & $12 \%$ & $20 \%$ & $25 \%$ \\
Abroad & 22153 & $10 \%$ & $1 \%$ & $4 \%$ & $86 \%$ \\
\hline \hline
\end{tabular}

Source: Statistics Netherlands, based on own calculations.

Table 3: Included variables in the models

\begin{tabular}{|c|c|}
\hline demographics & $\begin{array}{l}\text { gender, married, cohabiting, divorced, widowed, single par- } \\
\text { ent, Youngest child }<4 \text {, Youngest child } 5-12 \text {, Youngest child } \\
13-18,8 \text { age (at entry) intervals }\end{array}$ \\
\hline Country of origin & $\begin{array}{l}\text { Belgium, Germany, UK, France, new-EU (2004) countries, } \\
\text { Former Yugoslavia, rest of Europe (non EU- or EFTA- } \\
\text { countries), Morocco, rest of Africa, Turkey, Iran, Japan, In- } \\
\text { donesia, China, rest of Asia, Surinam, rest of Latin America, } \\
\text { USA/Canada, Australia }\end{array}$ \\
\hline $\begin{array}{l}\text { Income groups (except from } \\
\text { no-income) }\end{array}$ & $\begin{array}{l}\text { income }<€ 1000 \text { p.m., income } € 1000-€ 2000 \text { p.m. income } \\
€ 3000-€ 4000 \text { p.m., income } € 4000-€ 5000 \text { p.m. income } \\
>€ 5000 \text { p.m. (except from unemployment) }\end{array}$ \\
\hline $\begin{array}{l}\text { Employment sector (only if } \\
\text { origin state is employment) }\end{array}$ & $\begin{array}{l}\text { Agriculture, industry, construction, catering, transporta- } \\
\text { tion, finance, temporary services, cleaning, services, civil } \\
\text { services, education, health care, culture }\end{array}$ \\
\hline Self-employed & only from employment \\
\hline History & $\begin{array}{l}\text { previous immigration, previous emigration (only from } \\
\text { abroad), previous employment (from employment), previous } \\
\text { unemployment (from unemployment and no-income), previ- } \\
\text { ous no income (from unemployment and non-participation), } \\
\text { left the country from no income (from abroad), left the coun- } \\
\text { try from unemployment (from abroad) }\end{array}$ \\
\hline Business cycle indicators & Unemployment rate at entry, Unemployment rate \\
\hline
\end{tabular}


Table 4: Marginal effect on exit probability from EMPLOYMENT

\begin{tabular}{|c|c|c|c|}
\hline & unemployment & non-participation & abroad \\
\hline \multirow[t]{2}{*}{ female } & $0.026^{* * *}$ & $-0.011^{*}$ & $-0.014^{* * *}$ \\
\hline & $(0.004)$ & $(0.005)$ & $(0.004)$ \\
\hline \multirow[t]{2}{*}{ Married } & $0.046^{* * *}$ & $-0.020^{* *}$ & $-0.026^{* * *}$ \\
\hline & $(0.006)$ & $(0.007)$ & $(0.004)$ \\
\hline \multirow[t]{2}{*}{ Aged 18-25 } & $-0.008^{*}$ & $0.014^{*}$ & -0.006 \\
\hline & $(0.004)$ & $(0.006)$ & $(0.005)$ \\
\hline \multirow[t]{2}{*}{ Aged 55-60 } & $0.065^{* * *}$ & $-0.055^{* *}$ & -0.009 \\
\hline & $(0.017)$ & $(0.020)$ & $(0.013)$ \\
\hline \multirow{2}{*}{ Youngest child $<4$} & $0.019^{* * *}$ & $-0.055^{* * *}$ & $0.036^{* * *}$ \\
\hline & $(0.005)$ & $(0.008)$ & $(0.007)$ \\
\hline \multirow[t]{2}{*}{ Youngest child 5-12 } & 0.013 & $-0.058^{* * *}$ & $0.045^{* * *}$ \\
\hline & $(0.007)$ & $(0.011)$ & $(0.009)$ \\
\hline \multirow[t]{2}{*}{ self-employed } & $0.035^{* *}$ & -0.004 & $-0.031^{*}$ \\
\hline & $(0.012)$ & $(0.018)$ & $(0.016)$ \\
\hline \multirow[t]{2}{*}{ income $<1000$} & $0.024^{* * *}$ & $0.085^{* * *}$ & $-0.110^{* * *}$ \\
\hline & $(0.005)$ & $(0.009)$ & $(0.007)$ \\
\hline \multirow[t]{2}{*}{ income $1000-2000$} & $0.023^{* * *}$ & $0.031^{* * *}$ & $-0.054^{* * *}$ \\
\hline & $(0.004)$ & $(0.006)$ & $(0.005)$ \\
\hline \multirow{2}{*}{ income $3000-4000$} & $-0.024^{* * *}$ & $-0.036^{* * *}$ & $0.060^{* * *}$ \\
\hline & $(0.005)$ & $(0.008)$ & $(0.007)$ \\
\hline \multirow[t]{2}{*}{ income $4000-5000$} & $-0.035^{* * *}$ & $-0.064^{* * *}$ & $0.099^{* * *}$ \\
\hline & $(0.006)$ & $(0.011)$ & $(0.010)$ \\
\hline \multirow[t]{2}{*}{ income $>5000$} & $-0.053^{* * *}$ & $-0.098^{* * *}$ & $0.151^{* * *}$ \\
\hline & $(0.006)$ & $(0.010)$ & $(0.009)$ \\
\hline \multirow[t]{2}{*}{ Industry } & -0.009 & $-0.129^{* * *}$ & $0.138^{* * *}$ \\
\hline & $(0.005)$ & $(0.010)$ & $(0.009)$ \\
\hline \multirow[t]{2}{*}{ Catering } & $-0.030^{* * *}$ & $-0.029^{*}$ & $0.059^{* * *}$ \\
\hline & $(0.006)$ & $(0.012)$ & $(0.011)$ \\
\hline \multirow{2}{*}{ Transportation } & -0.002 & $-0.050^{* * *}$ & $0.052^{* * *}$ \\
\hline & $(0.006)$ & $(0.010)$ & $(0.009)$ \\
\hline \multirow[t]{2}{*}{ Finance } & -0.013 & $-0.039^{* *}$ & $0.052^{* * *}$ \\
\hline & $(0.010)$ & $(0.015)$ & $(0.012)$ \\
\hline \multirow[t]{2}{*}{ Services } & -0.005 & $-0.057^{* * *}$ & $0.062^{* * *}$ \\
\hline & $(0.005)$ & $(0.007)$ & $(0.006)$ \\
\hline \multirow[t]{2}{*}{ Education } & $0.093^{* * *}$ & $-0.219^{* * *}$ & $0.126^{* * *}$ \\
\hline & $(0.011)$ & $(0.014)$ & $(0.013)$ \\
\hline Africa & $0.018^{* *}$ & 0.016 & $-0.034^{* * *}$ \\
\hline & $(0.007)$ & $(0.009)$ & $(0.007)$ \\
\hline Japan & $-0.060^{* * *}$ & $-0.407^{* * *}$ & $0.467^{* * *}$ \\
\hline & $(0.009)$ & $(0.022)$ & $(0.023)$ \\
\hline USA/Canada & $-0.039^{* * *}$ & $0.020^{*}$ & $0.019^{*}$ \\
\hline & $(0.006)$ & $(0.010)$ & $(0.008)$ \\
\hline new-EU countries & $-0.025^{* * *}$ & $-0.052^{* * *}$ & $0.078^{* * *}$ \\
\hline & $(0.006)$ & $(0.012)$ & $(0.011)$ \\
\hline Belgium & $0.077^{* * *}$ & $-0.076^{* * *}$ & -0.001 \\
\hline & $(0.011)$ & $(0.013)$ & $(0.009)$ \\
\hline Germany & $0.037^{* * *}$ & $-0.032^{* * *}$ & -0.004 \\
\hline & $(0.006)$ & $(0.008)$ & $(0.006)$ \\
\hline UK & -0.001 & $0.030^{* * *}$ & $-0.029^{* * *}$ \\
\hline & $(0.004)$ & $(0.006)$ & $(0.005)$ \\
\hline Repeated entry & $-0.060^{* * *}$ & $-0.608^{* * *}$ & $0.669^{* * *}$ \\
\hline & $(0.006)$ & $(0.011)$ & $(0.011)$ \\
\hline Repeated employment & $0.028^{* * *}$ & $-0.094^{* * *}$ & $0.065^{* * *}$ \\
\hline & $(0.004)$ & $(0.006)$ & $(0.006)$ \\
\hline Unemployment rate at entry & -0.001 & $-0.020^{* * *}$ & $0.021^{* * *}$ \\
\hline & $(0.002)$ & $(0.004)$ & $(0.003)$ \\
\hline Unemployment rate & $0.010^{* * *}$ & $-0.059^{* * *}$ & $0.049^{* * *}$ \\
\hline & $(0.002)$ & $(0.003)$ & $(0.003)$ \\
\hline
\end{tabular}

Reference individual: Unemployment 8.5\%, NP 76.4\%, abroad $15.1 \%$. Only if one of the 3 marginal effects is significant they are shown. ${ }^{*} p<0.05,{ }^{* *} p<0.01$ and ${ }^{* * *} p<0.001$ 
Table 5: Marginal effect on exit probability from UNEMPLOYMENT

\begin{tabular}{l|ccc}
\hline \hline & employment & non-participation & abroad \\
\hline female & $-0.044^{* * *}$ & $0.040^{* * *}$ & 0.004 \\
Married & $(0.012)$ & $(0.011)$ & $(0.005)$ \\
& 0.023 & -0.001 & $-0.022^{* * *}$ \\
Divorced & $(0.013)$ & $(0.013)$ & $(0.006)$ \\
& $0.045^{*}$ & -0.025 & $-0.020^{*}$ \\
Widowed & $(0.021)$ & $(0.020)$ & $(0.008)$ \\
& $-0.388^{*}$ & $0.340^{*}$ & 0.047 \\
Aged 18-25 & $(0.164)$ & $(0.161)$ & $(0.027)$ \\
Aged 55-60 & $0.042^{* *}$ & $-0.039^{* *}$ & -0.003 \\
& $(0.016)$ & $(0.015)$ & $(0.006)$ \\
\hline income $<1000$ & $-0.128^{*}$ & $0.136^{*}$ & -0.008 \\
& $(0.056)$ & $(0.054)$ & $(0.015)$ \\
\hline Morocco & -0.018 & 0.003 & $0.015^{*}$ \\
China & $(0.016)$ & $(0.015)$ & $(0.008)$ \\
\hline \multirow{2}{*}{ other Asia } & $-0.091^{*}$ & $0.116^{* *}$ & -0.025 \\
& $(0.043)$ & $(0.042)$ & $(0.015)$ \\
UK & -0.143 & 0.018 & $0.125^{*}$ \\
& $(0.084)$ & $(0.080)$ & $(0.049)$ \\
\hline Repeated entry & $-0.071^{*}$ & 0.034 & $0.037^{*}$ \\
& $(0.035)$ & $(0.032)$ & $(0.017)$ \\
Repeated unemployment & -0.012 & -0.004 & $0.016^{*}$ \\
Repeated no-income & $(0.017)$ & $(0.015)$ & $(0.008)$ \\
\hline Unemployment rate & $(0.036)$ & $-0.046^{*}$ & $0.175^{* * *}$ \\
& $0.098^{* * *}$ & $(0.020)$ & $(0.044)$ \\
& $(0.012)$ & $-0.103^{* * *}$ & 0.005 \\
& $-0.464^{* * *}$ & $0.011)$ & $(0.006)$ \\
& $(0.028)$ & $(0.027)$ & $-0.027^{* * *}$ \\
& $0.022^{* *}$ & $-0.048^{* * *}$ & $0.007)$ \\
\hline \hline
\end{tabular}

Reference individual: Employment $72.6 \%$, NP $24.2 \%$, abroad $3.3 \%$. Only if one of the 3 marginal effects is significant they are shown. ${ }^{*} p<0.05,{ }^{* *} p<0.01$ and ${ }^{* * *} p<0.001$ 
Table 6: Marginal effect on exit probability from NON PARTICIPATION

\begin{tabular}{|c|c|c|c|}
\hline & employment & unemployment & abroad \\
\hline female & $\begin{array}{c}0.010 \\
(0.007)\end{array}$ & $\begin{array}{c}0.019^{* * *} \\
(0.004)\end{array}$ & $\begin{array}{c}-0.029^{* * *} \\
(0.007)\end{array}$ \\
\hline Married & $\begin{array}{l}0.020^{*} \\
(0.009)\end{array}$ & $\begin{array}{c}0.017^{* * *} \\
(0.005)\end{array}$ & $\begin{array}{c}-0.037^{* * *} \\
(0.008)\end{array}$ \\
\hline Cohabiting & $\begin{array}{l}0.163^{*} \\
(0.069)\end{array}$ & $\begin{array}{l}-0.015 \\
(0.031)\end{array}$ & $\begin{array}{l}-0.148^{*} \\
(0.065)\end{array}$ \\
\hline Divorced & $\begin{array}{c}0.102^{* * *} \\
(0.018)\end{array}$ & $\begin{array}{c}0.045^{* * *} \\
(0.010)\end{array}$ & $\begin{array}{c}-0.147^{* * *} \\
(0.016)\end{array}$ \\
\hline Aged 18-25 & $\begin{array}{c}0.061^{* * *} \\
(0.009)\end{array}$ & $\begin{array}{c}-0.024^{* * *} \\
(0.005)\end{array}$ & $\begin{array}{c}-0.037^{* * *} \\
(0.009)\end{array}$ \\
\hline Aged 45-50 & $\begin{array}{c}-0.041^{*} \\
(0.016)\end{array}$ & $\begin{array}{c}0.016 \\
(0.009)\end{array}$ & $\begin{array}{c}0.024 \\
(0.015)\end{array}$ \\
\hline Aged 50-55 & $\begin{array}{c}-0.081^{* * *} \\
(0.021)\end{array}$ & $\begin{array}{c}0.012 \\
(0.011)\end{array}$ & $\begin{array}{l}0.069^{* * *} \\
(0.020)\end{array}$ \\
\hline Aged 55-60 & $\begin{array}{c}-0.102^{* *} \\
(0.031)\end{array}$ & $\begin{array}{c}0.062^{* * *} \\
(0.018)\end{array}$ & $\begin{array}{c}0.040 \\
(0.030)\end{array}$ \\
\hline Africa & $\begin{array}{c}0.037^{* *} \\
(0.013)\end{array}$ & $\begin{array}{l}-0.001 \\
(0.007)\end{array}$ & $\begin{array}{c}-0.035^{* *} \\
(0.012)\end{array}$ \\
\hline Turkey & $\begin{array}{c}-0.063^{* *} \\
(0.021)\end{array}$ & $\begin{array}{l}-0.018 \\
(0.010)\end{array}$ & $\begin{array}{l}0.081^{* * *} \\
(0.021)\end{array}$ \\
\hline Japan & $\begin{array}{c}-0.240^{* * *} \\
(0.029)\end{array}$ & $\begin{array}{c}-0.093^{* * *} \\
(0.009)\end{array}$ & $\begin{array}{l}0.334^{* * *} \\
(0.030)\end{array}$ \\
\hline China & $\begin{array}{c}-0.161^{* * *} \\
(0.034)\end{array}$ & $\begin{array}{c}-0.055^{* * *} \\
(0.015)\end{array}$ & $\begin{array}{c}0.216^{* * *} \\
(0.035)\end{array}$ \\
\hline Indonesia & $\begin{array}{c}0.037 \\
(0.033)\end{array}$ & $\begin{array}{l}0.054^{*} \\
(0.021)\end{array}$ & $\begin{array}{c}-0.091^{* *} \\
(0.030)\end{array}$ \\
\hline other Asia & $\begin{array}{c}-0.164^{* * *} \\
(0.015)\end{array}$ & $\begin{array}{c}-0.033^{* * *} \\
(0.008)\end{array}$ & $\begin{array}{l}0.197^{* * *} \\
(0.015)\end{array}$ \\
\hline USA/Canada & $\begin{array}{c}-0.242^{* * *} \\
(0.013)\end{array}$ & $\begin{array}{c}-0.056^{* * *} \\
(0.007)\end{array}$ & $\begin{array}{l}0.299^{* * *} \\
(0.013)\end{array}$ \\
\hline Former Yugoslavia & $\begin{array}{c}-0.107^{*} \\
(0.042)\end{array}$ & $\begin{array}{l}0.067^{* *} \\
(0.026)\end{array}$ & $\begin{array}{c}0.039 \\
(0.042)\end{array}$ \\
\hline new-EU countries & $\begin{array}{c}0.082^{* * *} \\
(0.014)\end{array}$ & $\begin{array}{c}-0.032^{* * *} \\
(0.007)\end{array}$ & $\begin{array}{c}-0.050^{* * *} \\
(0.014)\end{array}$ \\
\hline Other Europe & $\begin{array}{c}-0.071^{* * *} \\
(0.018)\end{array}$ & $\begin{array}{l}-0.005 \\
(0.009)\end{array}$ & $\begin{array}{l}0.076^{* * *} \\
(0.018)\end{array}$ \\
\hline Germany & $\begin{array}{c}0.001 \\
(0.011)\end{array}$ & $\begin{array}{l}0.015^{*} \\
(0.006)\end{array}$ & $\begin{array}{l}-0.016 \\
(0.011)\end{array}$ \\
\hline UK & $\begin{array}{c}-0.056^{* * *} \\
(0.009)\end{array}$ & $\begin{array}{c}-0.012^{*} \\
(0.005)\end{array}$ & $\begin{array}{l}0.067^{* * *} \\
(0.008)\end{array}$ \\
\hline France & $\begin{array}{c}-0.106^{* * *} \\
(0.013)\end{array}$ & $\begin{array}{c}0.004 \\
(0.008)\end{array}$ & $\begin{array}{l}0.102^{* * *} \\
(0.013)\end{array}$ \\
\hline Repeated entry & $\begin{array}{c}-0.071^{* * *} \\
(0.015)\end{array}$ & $\begin{array}{c}-0.040^{* * *} \\
(0.003)\end{array}$ & $\begin{array}{l}0.111^{* * *} \\
(0.015)\end{array}$ \\
\hline Repeated unemployment & $\begin{array}{c}-0.279^{* * *} \\
(0.009)\end{array}$ & $\begin{array}{c}0.565^{* * *} \\
(0.017)\end{array}$ & $\begin{array}{c}-0.286^{* * *} \\
(0.012)\end{array}$ \\
\hline Repeated no-income & $\begin{array}{l}0.035^{*} \\
(0.014)\end{array}$ & $\begin{array}{c}-0.027^{* * *} \\
(0.007)\end{array}$ & $\begin{array}{l}-0.007 \\
(0.013)\end{array}$ \\
\hline Unemployment rate & $\begin{array}{c}-0.020^{* * *} \\
(0.003)\end{array}$ & $\begin{array}{c}0.029^{* * *} \\
(0.003)\end{array}$ & $\begin{array}{c}-0.009^{* *} \\
(0.003)\end{array}$ \\
\hline
\end{tabular}

Reference individual: Employment 47.4\%, Unemployment 10.1\%, abroad $42.6 \%$. Only if one of the 3 marginal effects is significant they are shown. ${ }^{*} p<0.05,{ }^{* *} p<0.01$ and ${ }^{* * *} p<0.001$ 
Table 7: Marginal effect on exit probability from ABROAD

\begin{tabular}{|c|c|c|c|}
\hline & employment & unemployment & non-participation \\
\hline female & $\begin{array}{c}-0.091^{* * *} \\
(0.020)\end{array}$ & $\begin{array}{c}0.008 \\
(0.014)\end{array}$ & $\begin{array}{c}0.083^{* * *} \\
(0.020)\end{array}$ \\
\hline Married & $\begin{array}{c}-0.109^{* * *} \\
(0.031)\end{array}$ & $\begin{array}{l}-0.016 \\
(0.019)\end{array}$ & $\begin{array}{c}0.125^{* * *} \\
(0.030)\end{array}$ \\
\hline Divorced & $\begin{array}{c}-0.239^{* * *} \\
(0.069)\end{array}$ & $\begin{array}{l}-0.004 \\
(0.015)\end{array}$ & $\begin{array}{c}0.243^{* * *} \\
(0.066)\end{array}$ \\
\hline Aged 35-40 & $\begin{array}{c}0.072^{*} \\
(0.030)\end{array}$ & $\begin{array}{l}-0.033 \\
(0.022)\end{array}$ & $\begin{array}{l}-0.039 \\
(0.026)\end{array}$ \\
\hline Aged 40-45 & $\begin{array}{c}0.083^{*} \\
(0.035) \\
\end{array}$ & $\begin{array}{l}-0.020 \\
(0.025) \\
\end{array}$ & $\begin{array}{c}-0.063^{*} \\
(0.028) \\
\end{array}$ \\
\hline income $<1000$ & $\begin{array}{c}0.014 \\
(0.051)\end{array}$ & $\begin{array}{l}-0.059^{*} \\
(0.024)\end{array}$ & $\begin{array}{c}0.045 \\
(0.048)\end{array}$ \\
\hline income 1000-2000 & $\begin{array}{c}0.037 \\
(0.046)\end{array}$ & $\begin{array}{l}-0.049^{*} \\
(0.023)\end{array}$ & $\begin{array}{c}0.012 \\
(0.044)\end{array}$ \\
\hline income $3000-4000$ & $\begin{array}{c}0.101^{*} \\
(0.052)\end{array}$ & $\begin{array}{l}-0.021 \\
(0.024)\end{array}$ & $\begin{array}{l}-0.080 \\
(0.047)\end{array}$ \\
\hline income $>5000$ & $\begin{array}{c}0.097^{*} \\
(0.048)\end{array}$ & $\begin{array}{l}-0.020 \\
(0.024)\end{array}$ & $\begin{array}{l}-0.077 \\
(0.045) \\
\end{array}$ \\
\hline Morocco & $\begin{array}{l}-0.246^{*} \\
(0.103)\end{array}$ & $\begin{array}{c}0.083 \\
(0.114)\end{array}$ & $\begin{array}{c}0.162 \\
(0.102)\end{array}$ \\
\hline Turkey & $\begin{array}{l}-0.052 \\
(0.087)\end{array}$ & $\begin{array}{c}0.079^{*} \\
(0.040)\end{array}$ & $\begin{array}{l}-0.027 \\
(0.087)\end{array}$ \\
\hline Japan & $\begin{array}{l}-0.097 \\
(0.059)\end{array}$ & $\begin{array}{l}0.110^{* *} \\
(0.037)\end{array}$ & $\begin{array}{l}-0.013 \\
(0.057)\end{array}$ \\
\hline Iran & $\begin{array}{l}-0.243 \\
(0.152)\end{array}$ & $\begin{array}{c}0.340^{*} \\
(0.157)\end{array}$ & $\begin{array}{l}-0.097 \\
(0.116)\end{array}$ \\
\hline China & $\begin{array}{c}-0.204 \\
(0.106)\end{array}$ & $\begin{array}{c}0.353^{* * *} \\
(0.106)\end{array}$ & $\begin{array}{l}-0.149^{*} \\
(0.072)\end{array}$ \\
\hline USA/Canada & $\begin{array}{c}0.093^{*} \\
(0.042)\end{array}$ & $\begin{array}{l}-0.003 \\
(0.033)\end{array}$ & $\begin{array}{l}-0.090^{*} \\
(0.036)\end{array}$ \\
\hline new-EU countries & $\begin{array}{c}0.214^{* * *} \\
(0.030)\end{array}$ & $\begin{array}{c}-0.065^{* *} \\
(0.025)\end{array}$ & $\begin{array}{c}-0.148^{* * *} \\
(0.023)\end{array}$ \\
\hline Germany & $\begin{array}{c}0.026 \\
(0.029) \\
\end{array}$ & $\begin{array}{c}0.022 \\
(0.024) \\
\end{array}$ & $\begin{array}{c}-0.048^{*} \\
(0.024)\end{array}$ \\
\hline Repeated departure & $\begin{array}{c}0.079^{*} \\
(0.040)\end{array}$ & $\begin{array}{c}-0.037^{*} \\
(0.019)\end{array}$ & $\begin{array}{c}-0.042 \\
(0.041)\end{array}$ \\
\hline no income in NL & $\begin{array}{c}-0.147^{* * *} \\
(0.037)\end{array}$ & $\begin{array}{c}0.068 \\
(0.043)\end{array}$ & $\begin{array}{c}0.080^{*} \\
(0.039)\end{array}$ \\
\hline unemployed in NL & $\begin{array}{c}-0.374^{* * *} \\
(0.031)\end{array}$ & $\begin{array}{c}0.285^{* * *} \\
(0.069)\end{array}$ & $\begin{array}{c}0.089 \\
(0.054)\end{array}$ \\
\hline Unemployment rate at entry & $\begin{array}{c}0.029^{*} \\
(0.014)\end{array}$ & $\begin{array}{l}-0.003 \\
(0.009)\end{array}$ & $\begin{array}{c}-0.026^{*} \\
(0.013)\end{array}$ \\
\hline Unemployment rate & $\begin{array}{c}0.117^{* * *} \\
(0.015)\end{array}$ & $\begin{array}{c}0.020 \\
(0.011)\end{array}$ & $\begin{array}{c}-0.137^{* * *} \\
(0.013)\end{array}$ \\
\hline
\end{tabular}

Reference individual: Employment $63.0 \%$, Unemployment $8.5 \%$, NP $28.4 \%$. Only if one of the 3 marginal effects is significant they are shown. ${ }^{*} p<0.05,{ }^{* *} p<0.01$ and ${ }^{* * *} p<0.001$ 
Table 8: Marginal effect on transition probability, 5 years after entry

\begin{tabular}{|c|c|c|c|c|}
\hline & employment & unemployment & non-participation & abroad \\
\hline female & $\begin{array}{c}0.003 \\
(0.008)\end{array}$ & $\begin{array}{l}0.005^{*} \\
(0.002)\end{array}$ & $\begin{array}{c}0.003 \\
(0.006)\end{array}$ & $\begin{array}{l}-0.011^{*} \\
(0.005)\end{array}$ \\
\hline Married & $\begin{array}{c}0.075^{* * *} \\
(0.008)\end{array}$ & $\begin{array}{c}0.001 \\
(0.002)\end{array}$ & $\begin{array}{c}-0.031^{* * *} \\
(0.005)\end{array}$ & $\begin{array}{c}-0.045^{* * *} \\
(0.005)\end{array}$ \\
\hline Cohabiting & $\begin{array}{c}0.069^{*} \\
(0.028)\end{array}$ & $\begin{array}{l}-0.002 \\
(0.004)\end{array}$ & $\begin{array}{l}-0.002 \\
(0.023)\end{array}$ & $\begin{array}{c}-0.066^{* *} \\
(0.022)\end{array}$ \\
\hline Divorced & $\begin{array}{c}0.093^{* * *} \\
(0.011)\end{array}$ & $\begin{array}{c}0.005 \\
(0.003)\end{array}$ & $\begin{array}{c}-0.030^{* * *} \\
(0.007)\end{array}$ & $\begin{array}{c}-0.068^{* * *} \\
(0.007)\end{array}$ \\
\hline Aged 18-25 & $\begin{array}{c}-0.005 \\
(0.008)\end{array}$ & $\begin{array}{l}-0.003 \\
(0.002)\end{array}$ & $\begin{array}{l}0.016^{* *} \\
(0.005)\end{array}$ & $\begin{array}{l}-0.008 \\
(0.006)\end{array}$ \\
\hline Aged 50-55 & $\begin{array}{c}-0.031^{*} \\
(0.015)\end{array}$ & $\begin{array}{c}0.013^{* * *} \\
(0.004)\end{array}$ & $\begin{array}{c}0.006 \\
(0.009)\end{array}$ & $\begin{array}{c}0.011 \\
(0.010)\end{array}$ \\
\hline Aged 55-60 & $\begin{array}{c}-0.096^{* * *} \\
(0.021)\end{array}$ & $\begin{array}{c}0.054^{* * *} \\
(0.012)\end{array}$ & $\begin{array}{c}0.003 \\
(0.011)\end{array}$ & $\begin{array}{l}0.038^{* *} \\
(0.013)\end{array}$ \\
\hline Youngest child $<4$ & $\begin{array}{c}0.013 \\
(0.008)\end{array}$ & $\begin{array}{c}0.002 \\
(0.002)\end{array}$ & $\begin{array}{c}-0.018^{* * *} \\
(0.005)\end{array}$ & $\begin{array}{c}0.003 \\
(0.006)\end{array}$ \\
\hline Youngest child 5-12 & $\begin{array}{c}0.042^{* * *} \\
(0.010)\end{array}$ & $\begin{array}{l}-0.001 \\
(0.002)\end{array}$ & $\begin{array}{c}-0.036^{* * *} \\
(0.005)\end{array}$ & $\begin{array}{c}-0.006 \\
(0.007)\end{array}$ \\
\hline Youngest child $13-18$ & $\begin{array}{l}0.033^{* *} \\
(0.012)\end{array}$ & $\begin{array}{l}-0.002 \\
(0.002)\end{array}$ & $\begin{array}{l}-0.018^{*} \\
(0.008)\end{array}$ & $\begin{array}{l}-0.012 \\
(0.011)\end{array}$ \\
\hline self-employed & $\begin{array}{l}0.152^{* * *} \\
(0.009)\end{array}$ & $\begin{array}{c}-0.006^{* * *} \\
(0.002)\end{array}$ & $\begin{array}{c}-0.055^{* * *} \\
(0.005)\end{array}$ & $\begin{array}{c}-0.091^{* * *} \\
(0.006)\end{array}$ \\
\hline income $<1000$ & $\begin{array}{c}-0.237^{* * *} \\
(0.011)\end{array}$ & $\begin{array}{c}0.049^{* * *} \\
(0.006)\end{array}$ & $\begin{array}{c}0.122^{* * * *} \\
(0.008)\end{array}$ & $\begin{array}{c}0.066^{* * *} \\
(0.010)\end{array}$ \\
\hline income $1000-2000$ & $\begin{array}{c}-0.074^{* * *} \\
(0.008)\end{array}$ & $\begin{array}{c}0.015^{* * *} \\
(0.002)\end{array}$ & $\begin{array}{c}0.046^{* * *} \\
(0.005)\end{array}$ & $\begin{array}{c}0.013^{*} \\
(0.006)\end{array}$ \\
\hline income $3000-4000$ & $\begin{array}{c}-0.047^{* * *} \\
(0.011)\end{array}$ & $\begin{array}{c}-0.007^{* * *} \\
(0.002)\end{array}$ & $\begin{array}{c}0.002 \\
(0.005)\end{array}$ & $\begin{array}{c}0.051^{* * *} \\
(0.008)\end{array}$ \\
\hline income $4000-5000$ & $\begin{array}{c}-0.082^{* * *} \\
(0.010)\end{array}$ & $\begin{array}{c}-0.007^{* * *} \\
(0.002)\end{array}$ & $\begin{array}{c}-0.003 \\
(0.006)\end{array}$ & $\begin{array}{c}0.093^{* * *} \\
(0.009)\end{array}$ \\
\hline income $>5000$ & $\begin{array}{c}-0.169^{* * *} \\
(0.010)\end{array}$ & $\begin{array}{c}-0.006^{* * *} \\
(0.002)\end{array}$ & $\begin{array}{c}0.009 \\
(0.006)\end{array}$ & $\begin{array}{c}0.166^{* * *} \\
(0.008)\end{array}$ \\
\hline Agriculture & $\begin{array}{c}-0.238^{* * *} \\
(0.019)\end{array}$ & $\begin{array}{l}0.006^{*} \\
(0.002)\end{array}$ & $\begin{array}{c}0.054^{* * *} \\
(0.008)\end{array}$ & $\begin{array}{c}0.178^{* * *} \\
(0.019)\end{array}$ \\
\hline Industry & $\begin{array}{c}-0.095^{* * *} \\
(0.009)\end{array}$ & $\begin{array}{c}0.001 \\
(0.002)\end{array}$ & $\begin{array}{l}-0.007 \\
(0.005)\end{array}$ & $\begin{array}{c}0.101^{* * *} \\
(0.007)\end{array}$ \\
\hline Construction & $\begin{array}{c}-0.154^{* * *} \\
(0.016)\end{array}$ & $\begin{array}{l}0.008^{* *} \\
(0.003)\end{array}$ & $\begin{array}{c}0.041^{* * *} \\
(0.007)\end{array}$ & $\begin{array}{c}0.104^{* * *} \\
(0.015)\end{array}$ \\
\hline Cleaning & $\begin{array}{c}-0.141^{* * *} \\
(0.014)\end{array}$ & $\begin{array}{c}0.004 \\
(0.002)\end{array}$ & $\begin{array}{c}0.024^{* * *} \\
(0.006)\end{array}$ & $\begin{array}{c}0.114^{* * *} \\
(0.012)\end{array}$ \\
\hline Catering & $\begin{array}{c}-0.188^{* * *} \\
(0.011)\end{array}$ & $\begin{array}{c}0.004 \\
(0.002)\end{array}$ & $\begin{array}{c}0.037^{* * *} \\
(0.006)\end{array}$ & $\begin{array}{c}0.147^{* * *} \\
(0.011)\end{array}$ \\
\hline Transportation & $\begin{array}{c}-0.091^{* * *} \\
(0.009)\end{array}$ & $\begin{array}{l}0.004^{*} \\
(0.002)\end{array}$ & $\begin{array}{c}0.013^{*} \\
(0.005)\end{array}$ & $\begin{array}{c}0.074^{* * *} \\
(0.008)\end{array}$ \\
\hline Finance & $\begin{array}{c}-0.052^{* * *} \\
(0.010)\end{array}$ & $\begin{array}{l}-0.001 \\
(0.002)\end{array}$ & $\begin{array}{c}0.005 \\
(0.006)\end{array}$ & $\begin{array}{c}0.048^{* * *} \\
(0.008)\end{array}$ \\
\hline Temporary services & $\begin{array}{c}-0.333^{* * *} \\
(0.010)\end{array}$ & $\begin{array}{c}0.021^{* * *} \\
(0.003)\end{array}$ & $\begin{array}{c}0.091^{* * *} \\
(0.007)\end{array}$ & $\begin{array}{c}0.222^{* * *} \\
(0.010)\end{array}$ \\
\hline Services & $\begin{array}{c}-0.119^{* * *} \\
(0.010)\end{array}$ & $\begin{array}{l}0.006^{* *} \\
(0.002)\end{array}$ & $\begin{array}{c}0.019^{* * *} \\
(0.005)\end{array}$ & $\begin{array}{c}0.094^{* * *} \\
(0.008)\end{array}$ \\
\hline Education & $\begin{array}{l}-0.006 \\
(0.009)\end{array}$ & $\begin{array}{c}0.007^{* * *} \\
(0.002)\end{array}$ & $\begin{array}{c}-0.040^{* * *} \\
(0.005)\end{array}$ & $\begin{array}{c}0.038^{* * *} \\
(0.008)\end{array}$ \\
\hline Health Care & $\begin{array}{c}-0.014 \\
(0.013)\end{array}$ & $\begin{array}{l}-0.002 \\
(0.002)\end{array}$ & $\begin{array}{c}-0.019^{* *} \\
(0.006)\end{array}$ & $\begin{array}{l}0.035^{* *} \\
(0.011)\end{array}$ \\
\hline
\end{tabular}

Only if one of the 4 marginal effects is significant they are shown. $* p<0.05, * *$ $p<0.01$ and $* * * p<0.001$. Reference individual after 5 years: employment $74.8 \%$; unemployment $1.2 \%$; NP $10.5 \%$; abroad $13.5 \%$. 
Table 8: Marginal effect on transition probability, 5 years after entry (continued)

\begin{tabular}{l|cccc}
\hline \hline & employment & unemployment & non-participation & abroad \\
\hline Turkey & $-0.106^{* * *}$ & 0.004 & $0.045^{* * *}$ & $0.056^{* * *}$ \\
Japan & $(0.017)$ & $(0.003)$ & $(0.009)$ & $(0.014)$ \\
& $-0.037^{* *}$ & $-0.008^{* * *}$ & $-0.069^{* * *}$ & $0.114^{* * *}$ \\
other Asia & $(0.012)$ & $(0.002)$ & $(0.006)$ & $(0.012)$ \\
& $-0.049^{* * *}$ & -0.002 & $0.024^{* * *}$ & $0.028^{* *}$ \\
USA/Canada & $(0.012)$ & $(0.002)$ & $(0.007)$ & $(0.010)$ \\
& $-0.137^{* * *}$ & $-0.005^{*}$ & $0.066^{* * *}$ & $0.076^{* * *}$ \\
Morocco & $(0.013)$ & $(0.002)$ & $(0.008)$ & $(0.010)$ \\
Africa & 0.010 & $0.019^{* * *}$ & 0.004 & $-0.033^{*}$ \\
Former Yugoslavia & $(0.020)$ & $(0.005)$ & $(0.011)$ & $(0.015)$ \\
& $0.055^{* * *}$ & -0.001 & -0.009 & $-0.045^{* * *}$ \\
new-EU countries & $(0.009)$ & $(0.002)$ & $(0.006)$ & $(0.007)$ \\
& $0.058^{* *}$ & 0.002 & -0.013 & $-0.047^{* *}$ \\
Other Europe & $(0.022)$ & $(0.005)$ & $(0.012)$ & $(0.015)$ \\
Belgium & $0.065^{* * *}$ & $-0.008^{* * *}$ & $-0.027^{* * *}$ & $-0.030^{* * *}$ \\
& $(0.010)$ & $(0.001)$ & $(0.006)$ & $(0.007)$ \\
Germany & $0.050^{* * *}$ & $-0.005^{* *}$ & 0.005 & $-0.050^{* * *}$ \\
& $(0.012)$ & $(0.002)$ & $(0.007)$ & $(0.009)$ \\
UK & $0.066^{* * *}$ & 0.004 & $-0.041^{* * *}$ & $-0.030^{* * *}$ \\
& $(0.009)$ & $(0.002)$ & $(0.005)$ & $(0.007)$ \\
France & $0.031^{* * *}$ & 0.004 & $-0.017^{* * *}$ & $-0.018^{* *}$ \\
& $(0.009)$ & $(0.002)$ & $(0.005)$ & $(0.007)$ \\
Unemployment rate & -0.012 & 0.000 & $0.021^{* * *}$ & -0.009 \\
& $(0.009)$ & $(0.002)$ & $(0.005)$ & $(0.007)$ \\
\hline \hline
\end{tabular}

Only if one of the 4 marginal effects is significant they are shown. $* p<0.05, * * p<0.01$ and $* * * p<0.001$. Reference individual after 5 years: employment $74.8 \%$; unemployment $1.2 \%$; NP $10.5 \%$; abroad $13.5 \%$.

Table 9: Frequency- and time-indicators of base Scenario

\begin{tabular}{l|cccc}
\hline \hline & employed & unemployed & non-participation & abroad \\
Time spent in state (mos) & 76.2 & 3.6 & 17.2 & 22.8 \\
Av. \# spells & 2.30 & 0.57 & 1.55 & 0.49 \\
Av. \# spells (cond) & 2.30 & 1.87 & 2.25 & 1.19 \\
Av. spell length (mos) & 33.4 & 6.3 & 11.1 & 45.7 \\
& \multicolumn{4}{c}{ Probability (\%) } \\
after 10 yrs & 50.5 & 4.1 & 13.2 & 32.2 \\
within 10 yrs & 100 & 30.3 & 68.9 & 41.4 \\
$\geq 6$ mos & 98.0 & 15.9 & 53.6 & 39.0 \\
$\geq 1$ yr & 95.4 & 9.3 & 42.8 & 36.7 \\
$\geq 2$ yrs & 88.9 & 4.7 & 27.6 & 32.8 \\
$\geq 5$ yrs & 65.5 & 0.6 & 7.0 & 18.7 \\
10 yrs & 16.9 & \multicolumn{4}{c}{} \\
\hline \hline
\end{tabular}


Table 10: Change in frequency- and time-indicators for alternative Scenario's (difference with base scenario)

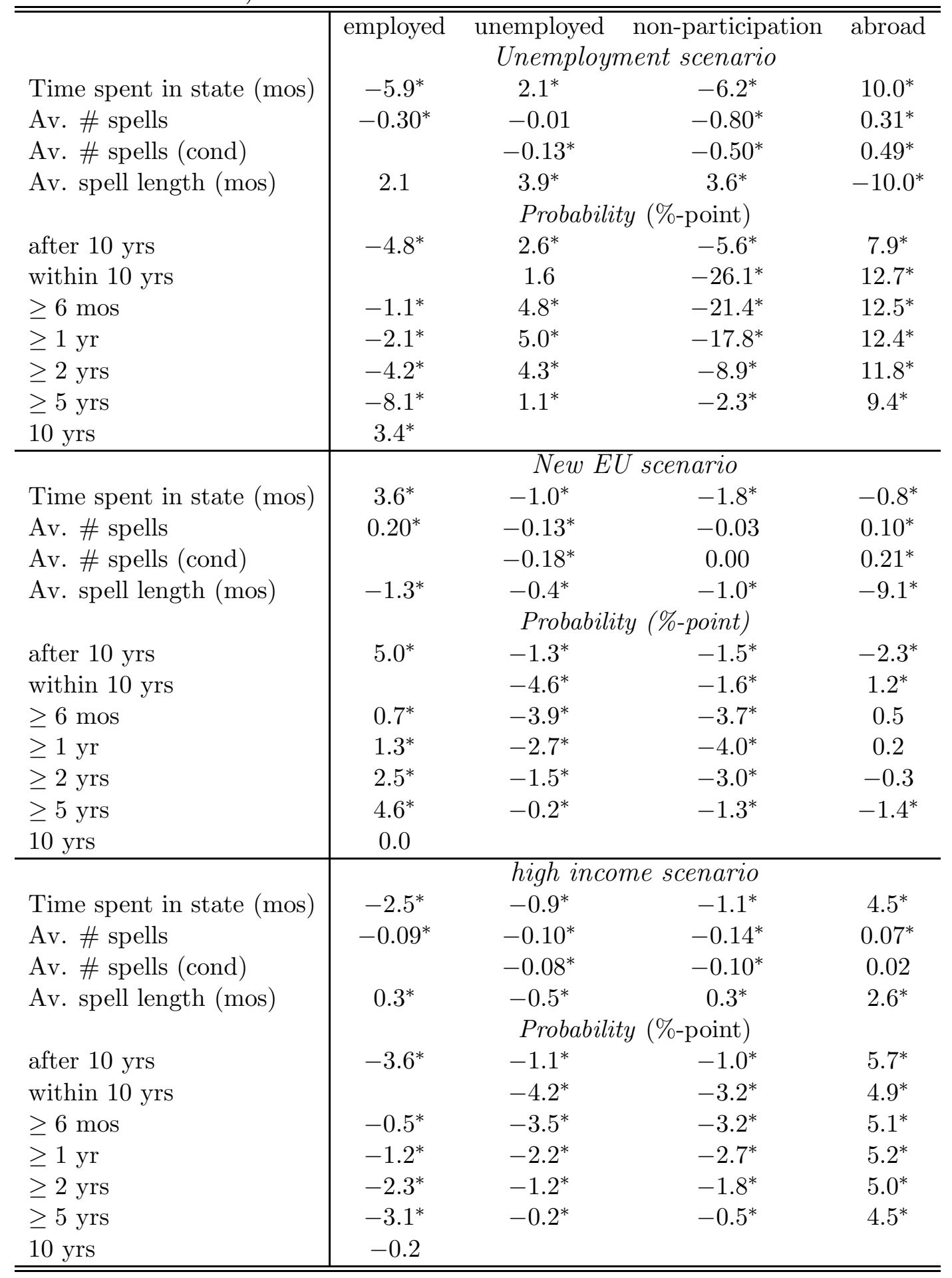

$* p<0.05$ 
Table 11: Most frequent paths for all scenario's

\begin{tabular}{l|cccc}
\hline \hline & \multicolumn{4}{|c}{ Percentage of paths } \\
path & base & unemployment & new EU & high income \\
\hline 1 & 16.9 & $20.3^{*}$ & 16.9 & 16.7 \\
131 & 7.8 & $2.7^{*}$ & $8.7^{*}$ & $7.5^{*}$ \\
14 & 7.7 & $13.9^{*}$ & $6.8^{*}$ & $10.7^{*}$ \\
134 & 5.7 & $1.9^{*}$ & $3.4^{*}$ & 5.5 \\
1314 & 4.2 & $2.6^{*}$ & $4.6^{*}$ & $5.7^{*}$ \\
13 & 3.3 & $4.0^{*}$ & $2.8^{*}$ & 3.3 \\
13131 & 3.1 & $0.4^{*}$ & $3.9^{*}$ & 2.9 \\
1313 & 2.4 & $0.9^{*}$ & $2.1^{*}$ & 2.4 \\
13134 & 2.3 & $0.3^{*}$ & $1.6^{*}$ & 2.2 \\
1341 & 1.5 & $0.7^{*}$ & 1.4 & $1.3^{*}$ \\
141 & 1.4 & $3.5^{*}$ & $2.1^{*}$ & 1.4 \\
1414 & 1.3 & $5.0^{*}$ & $1.8^{*}$ & $1.8^{*}$ \\
13231 & 1.1 & 0.8 & $0.9^{*}$ & 1.3 \\
131313 & 1.1 & $0.1^{*}$ & $1.2^{*}$ & 1.1 \\
131314 & 1.1 & $0.3^{*}$ & $1.4^{*}$ & $1.5^{*}$ \\
121 & 1.0 & 1.1 & $0.8^{*}$ & $0.8^{*}$ \\
\hline sum & 61.8 & 57.9 & 60.5 & 65.6 \\
\hline \hline
\end{tabular}

Most frequent paths are ordered for base scenario. In path: 1=employment; $2=$ unemployment; 3 = non-participation; $4=$ abroad. * differs significantly (95\%) from base scenario. 
Table 12: Average duration (in months) in each state for the most frequent paths for all scenario's

\begin{tabular}{|c|c|c|c|c|c|}
\hline path & state & base & $\begin{array}{l}\text { Average durat } \\
\text { unemployment }\end{array}$ & $\begin{array}{l}\text { on in each } \\
\text { new EU }\end{array}$ & $\begin{array}{l}\text { state } \\
\text { high income }\end{array}$ \\
\hline 1 & employment & 120 & 120 & 120 & 120 \\
\hline \multirow[t]{3}{*}{131} & employment & 57.7 & $53.4^{-}$ & $60.8^{+}$ & 58.4 \\
\hline & non-participation & 17.2 & $22.7^{+}$ & $14.4^{-}$ & 17.2 \\
\hline & employment & 45.1 & 44.0 & 44.8 & 44.4 \\
\hline \multirow[t]{2}{*}{14} & employment & 38.8 & 39.8 & $40.9^{+}$ & $36.8^{-}$ \\
\hline & abroad & 81.2 & 80.2 & $79.1^{-}$ & $83.1^{+}$ \\
\hline \multirow[t]{3}{*}{134} & employment & 43.1 & 44.7 & $45.6^{+}$ & 41.7 \\
\hline & non-participation & 16.9 & $24.0^{+}$ & $16.0^{-}$ & 16.9 \\
\hline & abroad & 60.1 & $51.3^{-}$ & 58.4 & 61.3 \\
\hline \multirow[t]{4}{*}{1314} & employment & 27.2 & 27.2 & $31.9^{+}$ & 28.0 \\
\hline & non-participation & 14.2 & $18.9^{+}$ & $12.9^{-}$ & 13.8 \\
\hline & employment & 23.9 & 23.0 & 24.9 & 23.7 \\
\hline & abroad & 54.7 & $50.9^{-}$ & $50.2^{-}$ & 54.4 \\
\hline \multirow[t]{2}{*}{13} & employment & 94.8 & $88.4^{-}$ & $98.2^{+}$ & 94.9 \\
\hline & non-participation & 25.2 & $31.6^{+}$ & $21.8^{-}$ & 25.1 \\
\hline \multirow[t]{5}{*}{13131} & employment & 34.0 & $29.3^{-}$ & $36.2^{+}$ & 35.3 \\
\hline & non-participation & 13.6 & 14.3 & 13.1 & 14.0 \\
\hline & employment & 28.0 & $24.1^{-}$ & 27.6 & $25.8^{-}$ \\
\hline & non-participation & 14.2 & $20.8^{+}$ & 13.5 & 14.9 \\
\hline & employment & 30.3 & 31.6 & 29.6 & 30.0 \\
\hline \multirow[t]{4}{*}{1313} & employment & 42.5 & $36.6^{-}$ & $46.3^{+}$ & 42.7 \\
\hline & non-participation & 23.8 & $28.1^{+}$ & $20.7^{-}$ & 23.9 \\
\hline & employment & 31.4 & $27.8^{-}$ & 33.2 & 31.3 \\
\hline & non-participation & 22.3 & $27.5^{+}$ & $19.8^{-}$ & 22.1 \\
\hline \multirow[t]{5}{*}{13134} & employment & 25.5 & $21.6^{-}$ & 26.3 & 25.7 \\
\hline & non-participation & 14.0 & 17.3 & 13.6 & 14.0 \\
\hline & employment & 19.9 & 19.4 & $21.7^{+}$ & 19.4 \\
\hline & non-participation & 15.0 & $22.5^{+}$ & 14.5 & 15.4 \\
\hline & abroad & 45.7 & $39.3^{-}$ & 43.8 & 45.4 \\
\hline \multirow[t]{4}{*}{1341} & employment & 30.9 & 32.8 & 33.3 & 29.3 \\
\hline & non-participation & 14.4 & $21.3^{+}$ & 14.3 & 14.7 \\
\hline & abroad & 40.7 & 37.4 & $37.8^{-}$ & $43.7^{+}$ \\
\hline & employment & 33.9 & $28.5^{-}$ & 34.6 & 32.4 \\
\hline \multirow[t]{3}{*}{141} & employment & 32.9 & $38.9^{+}$ & $36.8^{+}$ & 32.3 \\
\hline & abroad & 50.6 & 52.1 & $44.7^{-}$ & $54.6^{+}$ \\
\hline & employment & 36.5 & $29.0^{-}$ & 38.5 & $33.2^{-}$ \\
\hline
\end{tabular}

Most frequent paths are ordered for base scenario. In path: $1=$ employment; $2=$ unemployment; $3=$ non-participation; $4=$ abroad. + significantly (95\%) longer; - significantly (95\%) shorter. 


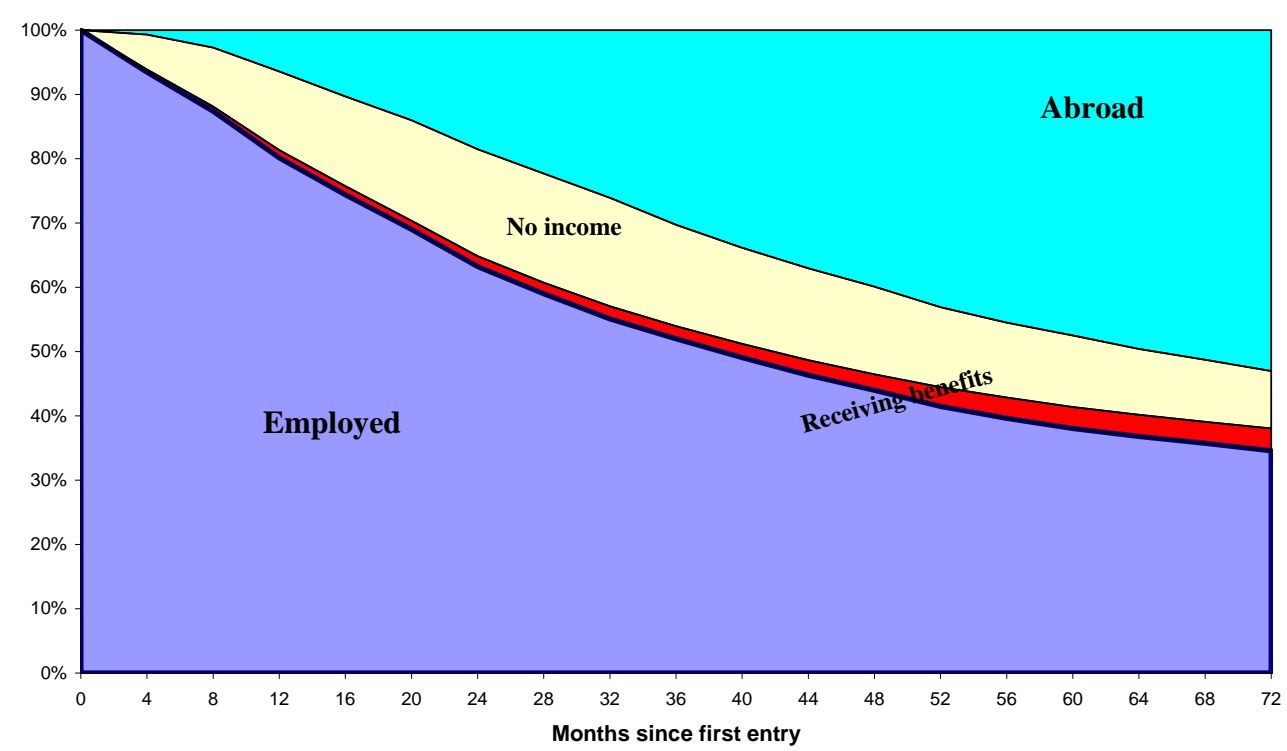

Figure 1: Development of SES of labour immigrants arriving in 1999

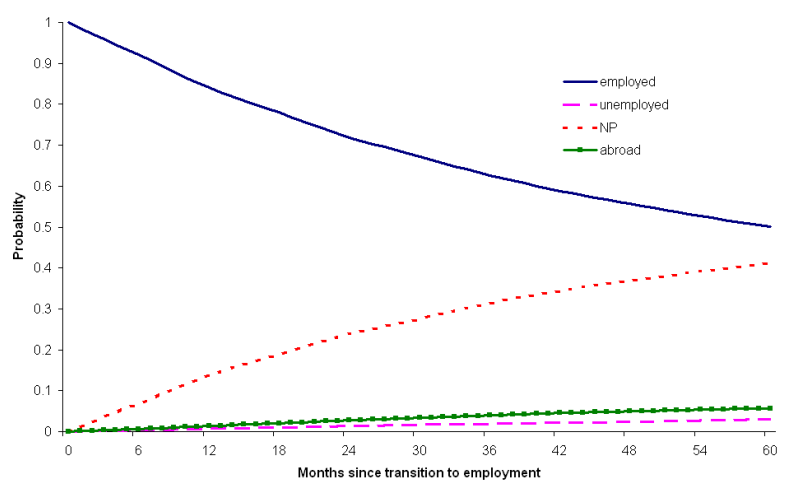

Employment

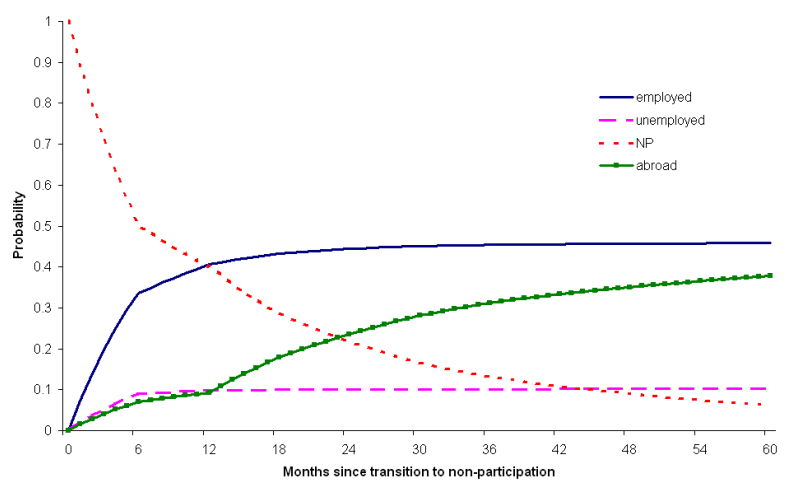

Non-participation

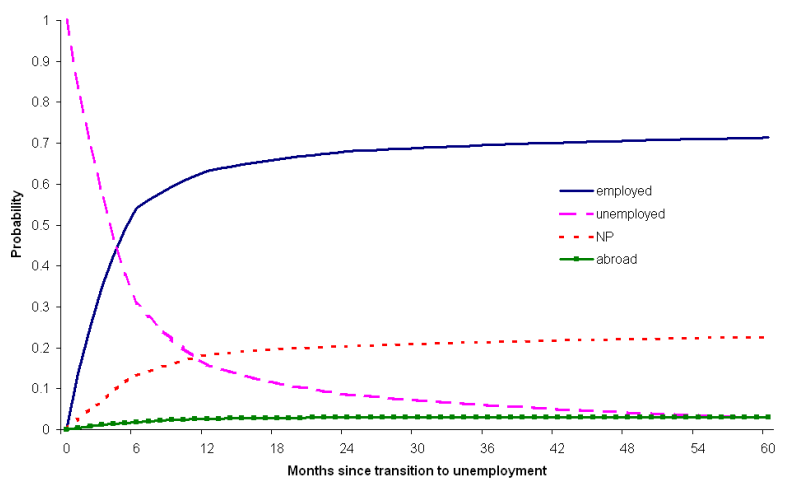

Unemployment

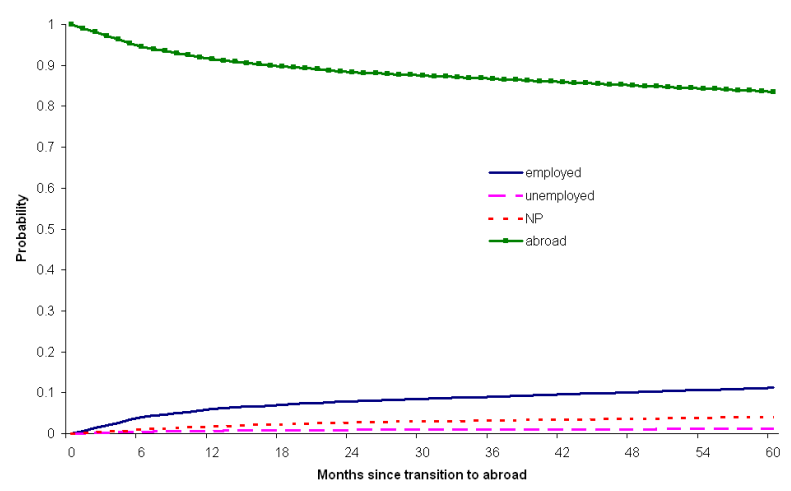

Abroad

Figure 2: Survival rate and cumulative incidence functions 


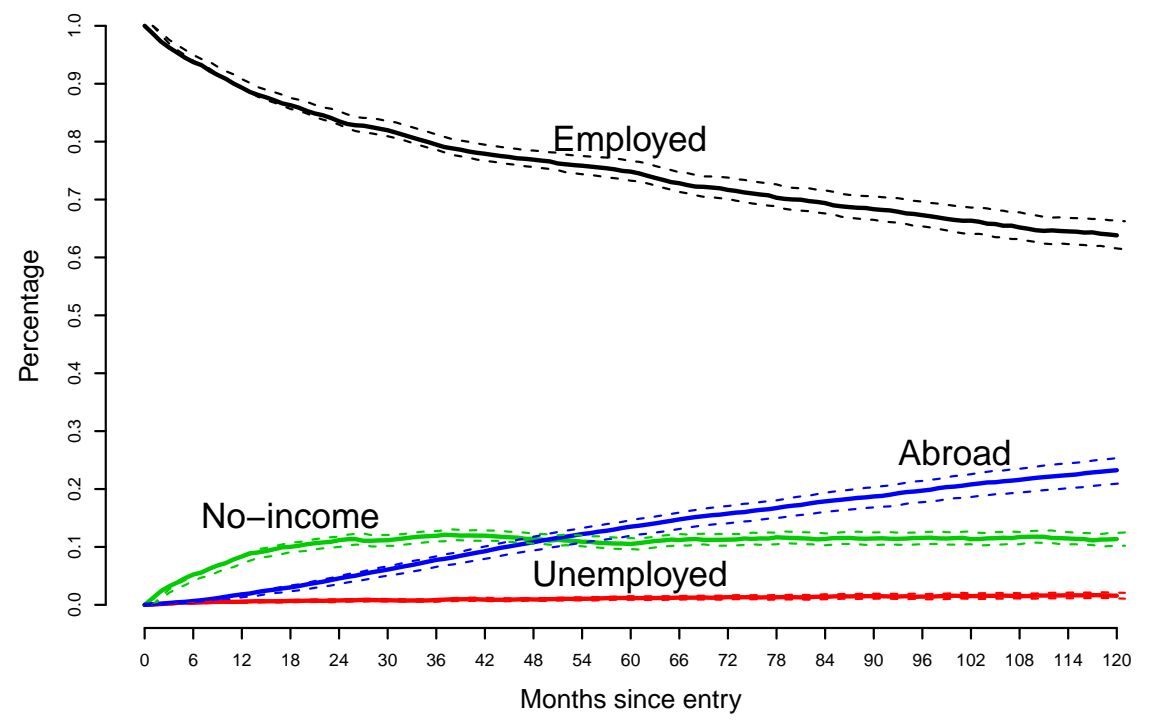

Figure 3: Development of transition probability with $95 \%$ confidence bands of employed immigrants (reference individual) 

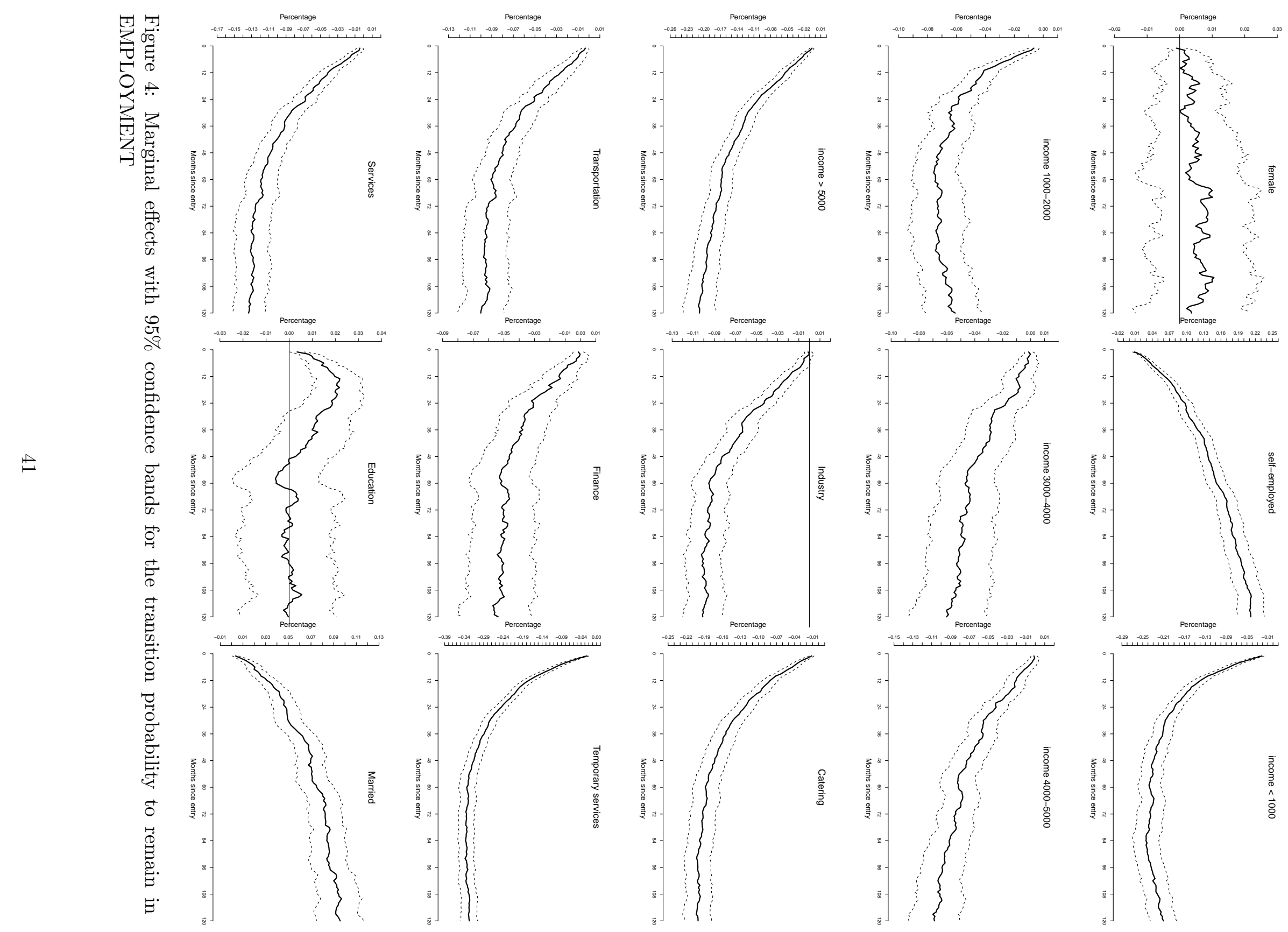

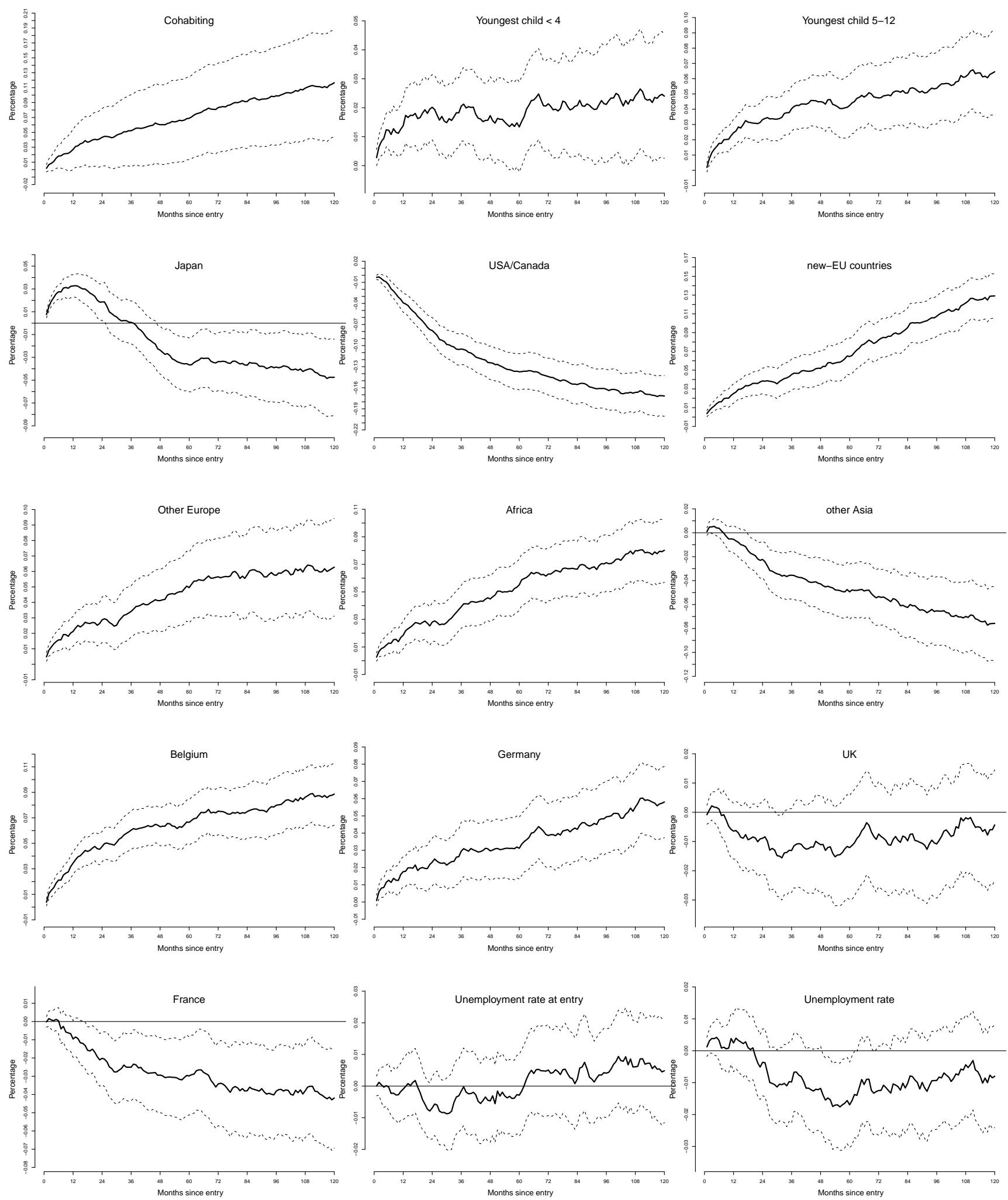

Figure 4: Marginal effects with 95\% confidence bands for the transition probability to EMPLOYMENT (continued) 

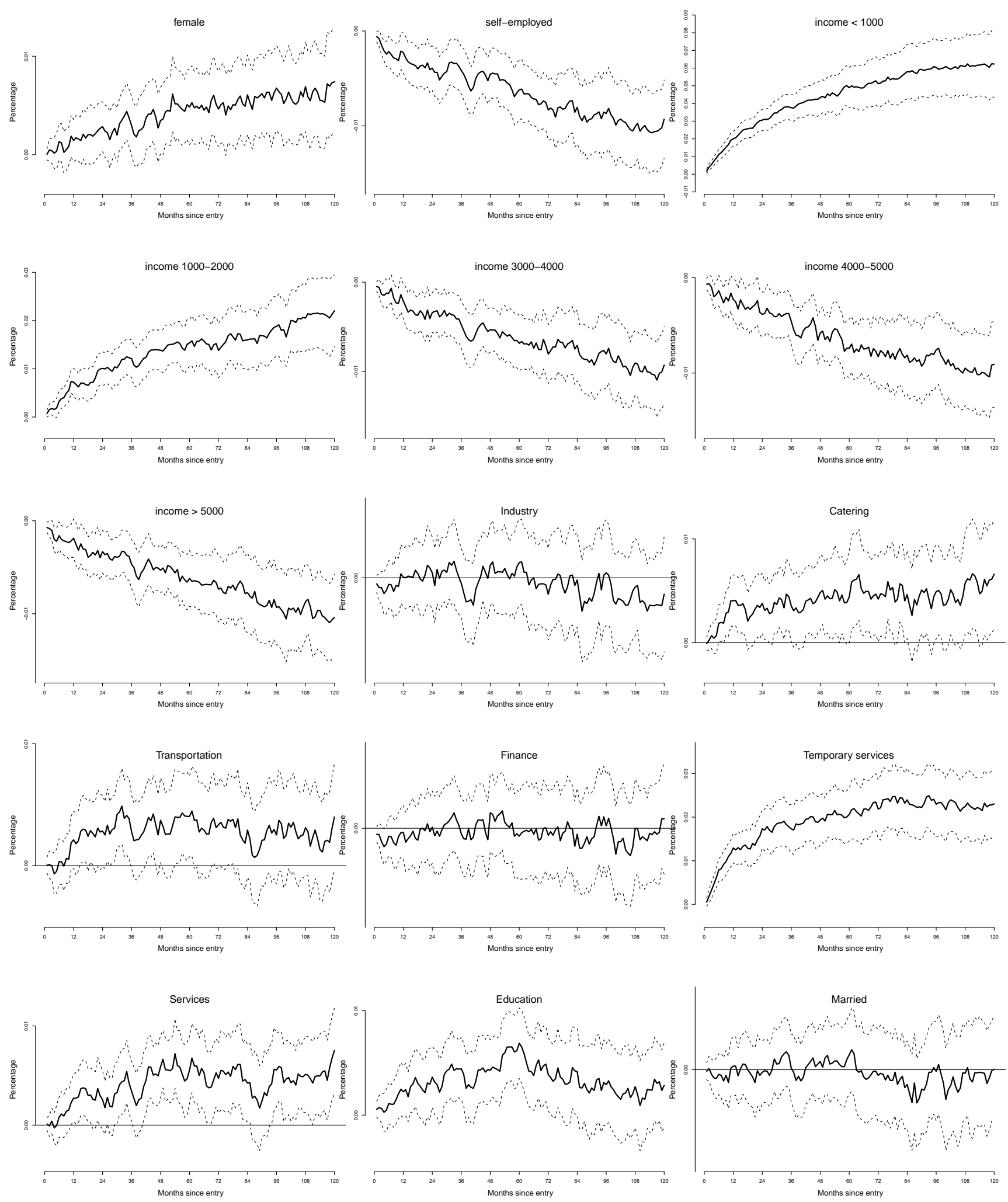

Figure 5: Marginal effects with 95\% confidence bands for the transition probability to UNEMPLOYMENT 

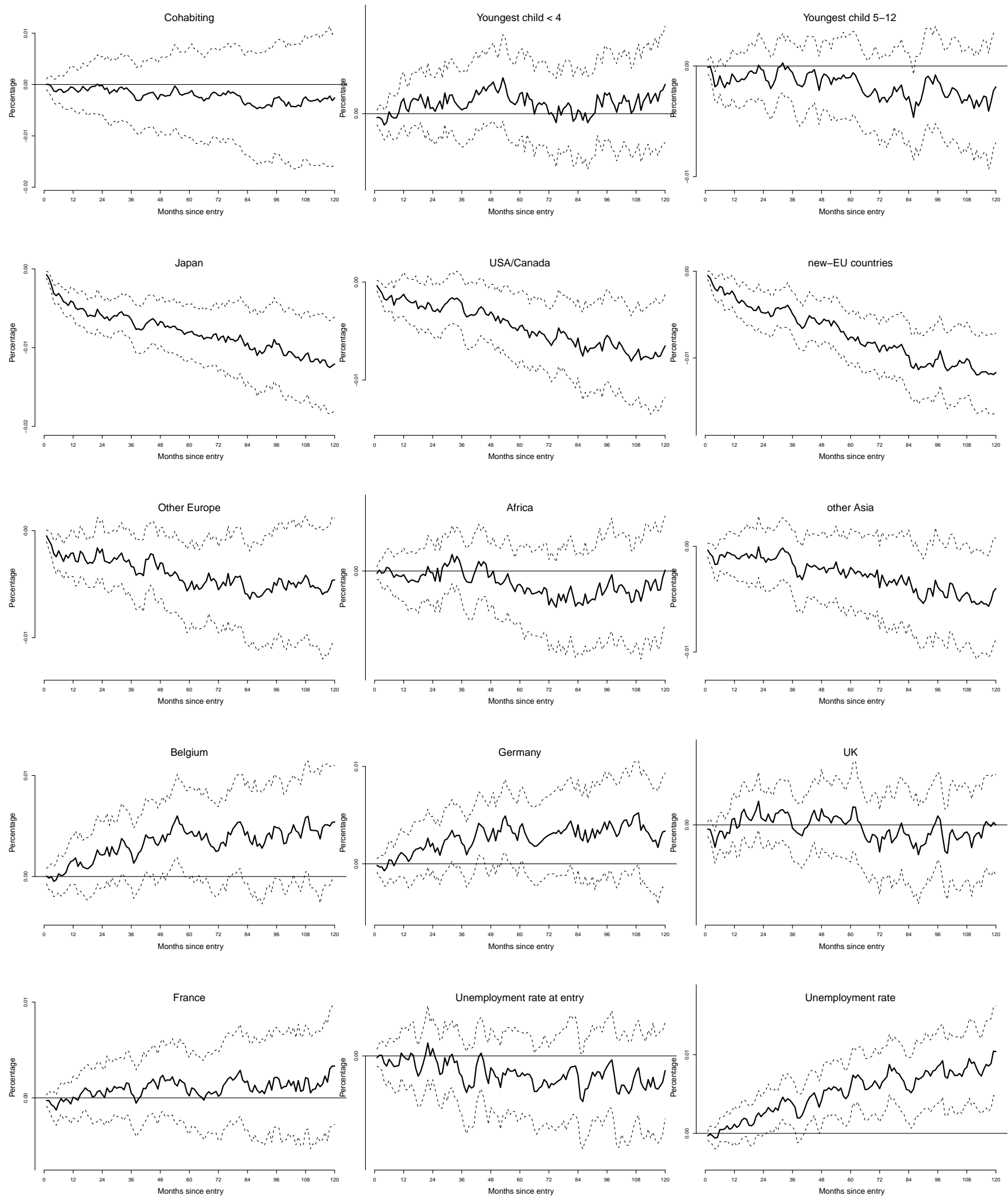

Figure 5: Marginal effects with 95\% confidence bands for the transition probability to UNEMPLOYMENT (continued) 

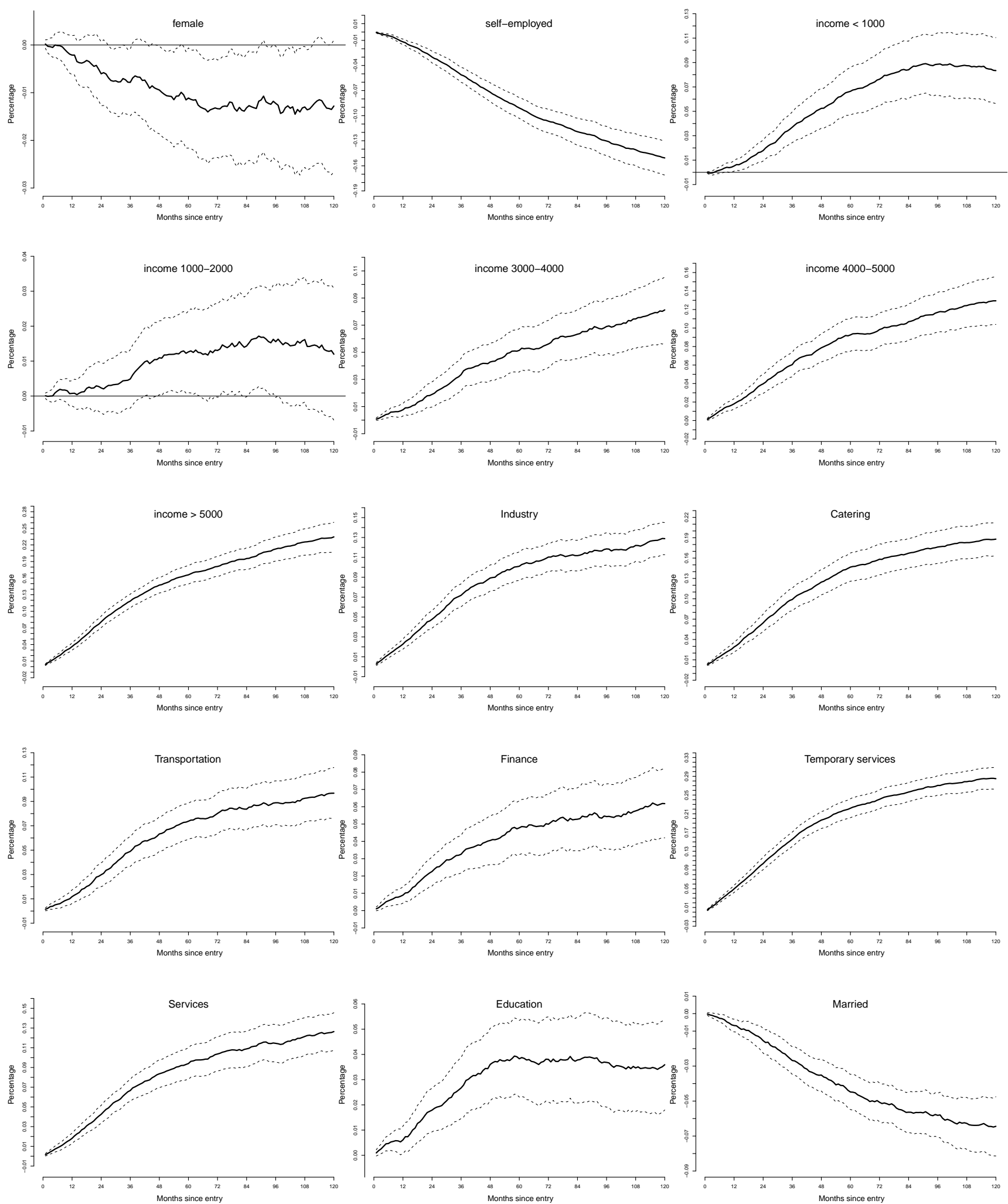

Figure 6: Marginal effects with $95 \%$ confidence bands for the transition probability to ABROAD 

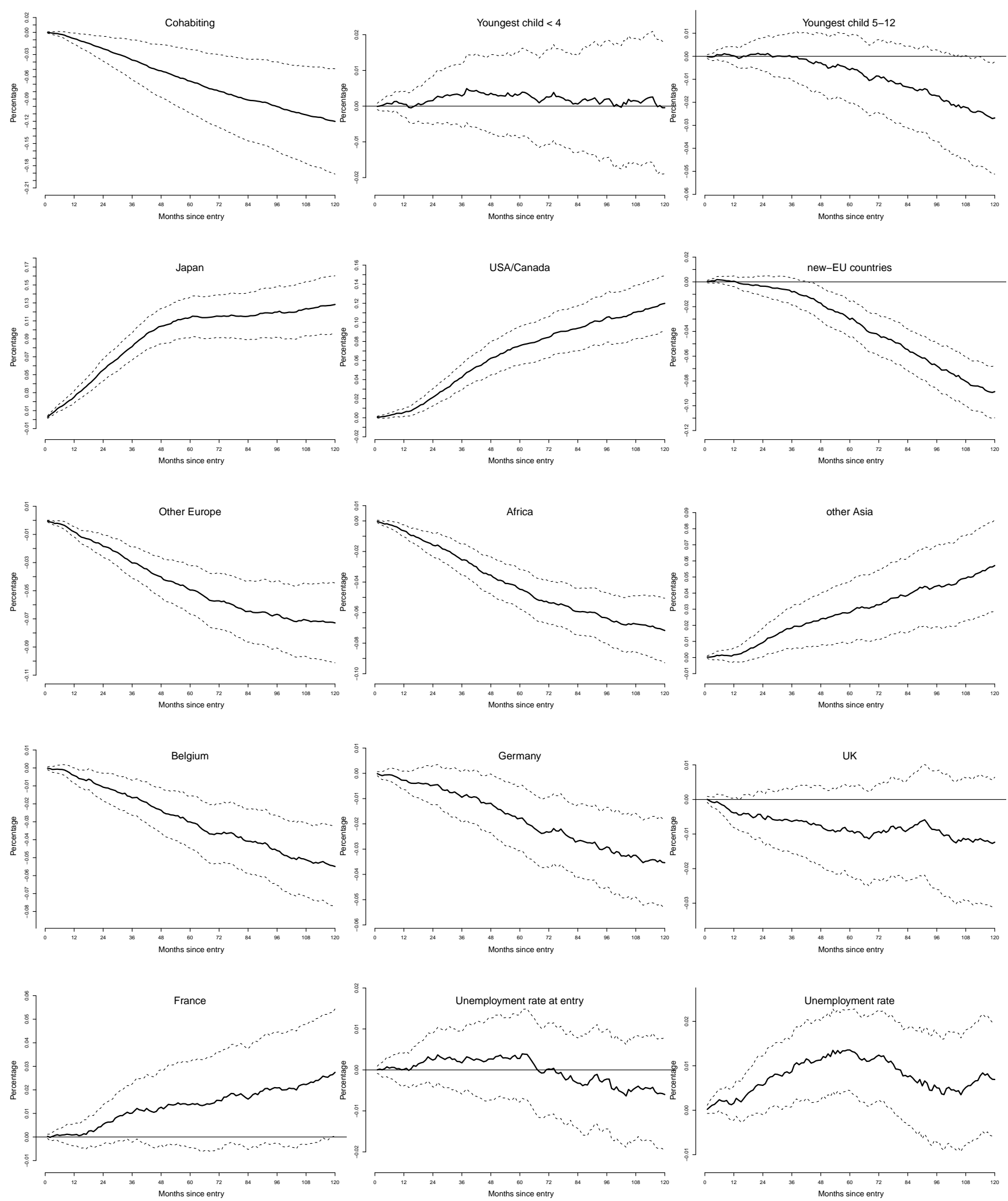

Figure 6: Marginal effects with $95 \%$ confidence bands for the transition probability to ABROAD (continued) 

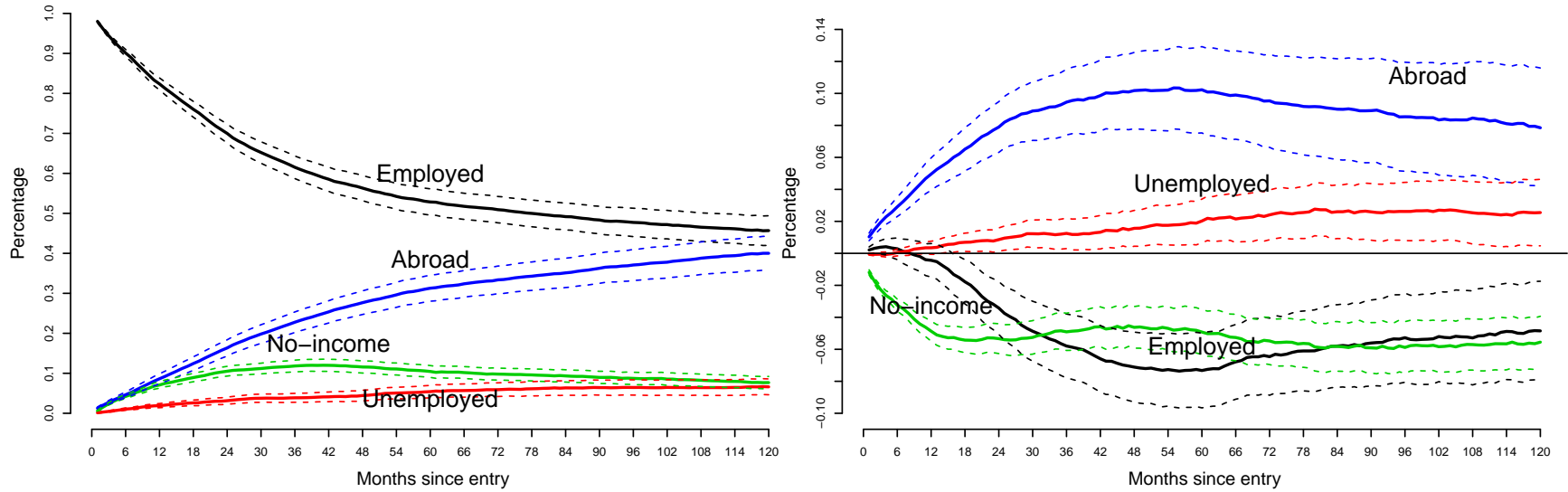

\section{Unemployment scenario}
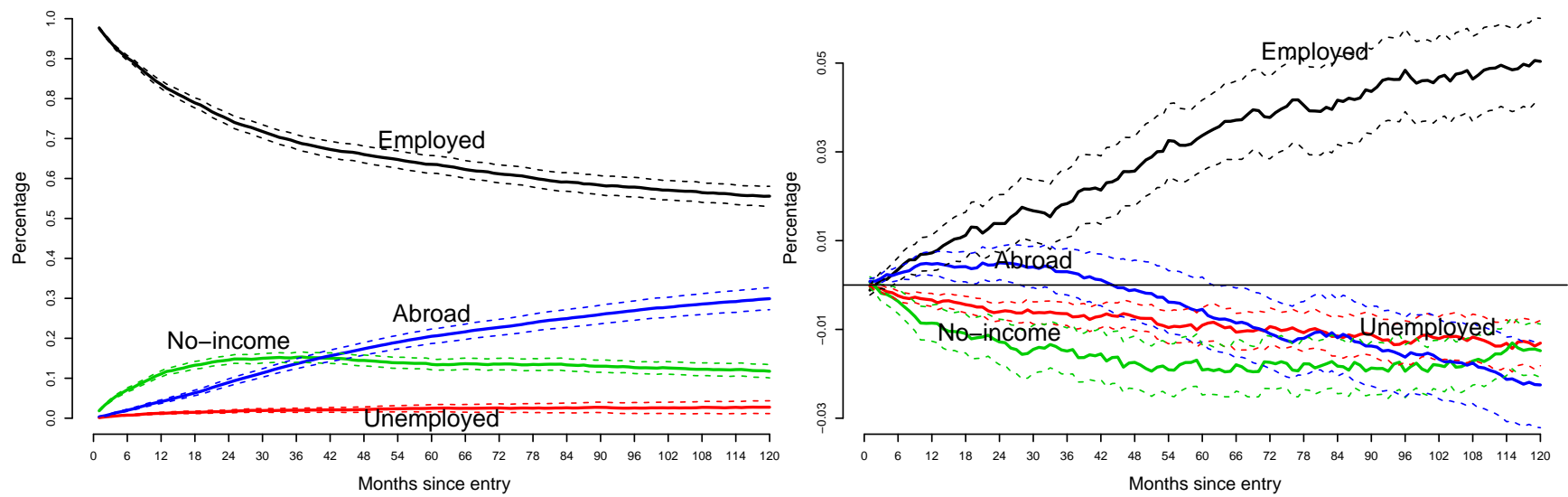

New EU scenario
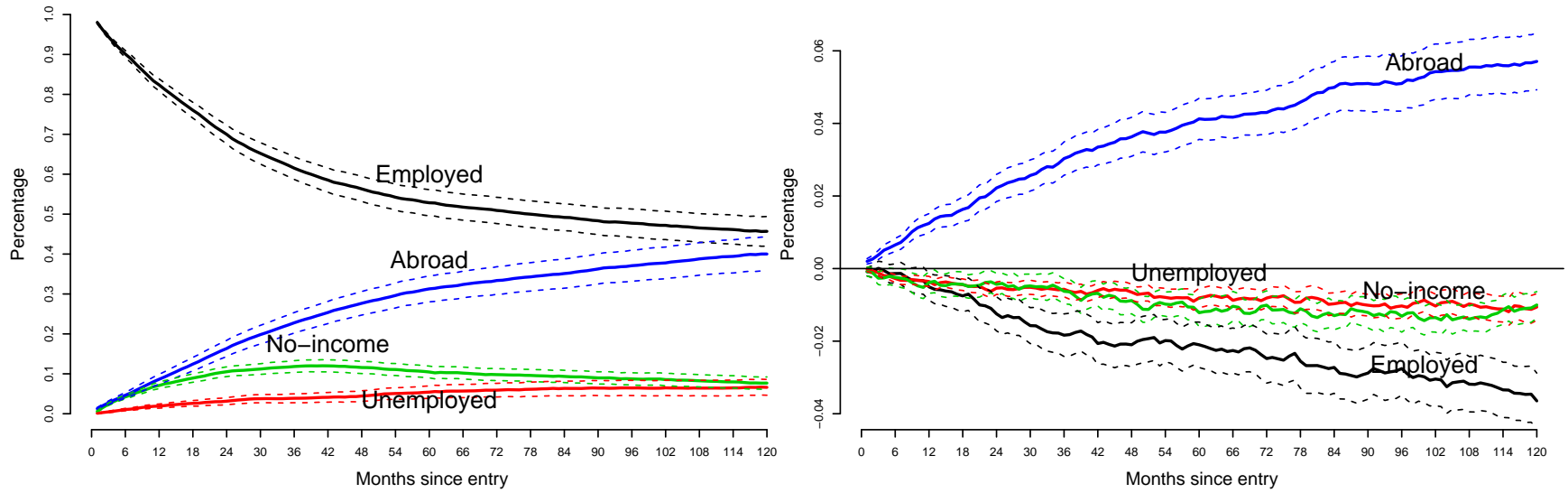

\section{High Income scenario}

Figure 7: Transition probabilities in scenario's (left) and change in transition probabilities w.r.t. base scenario (right) 

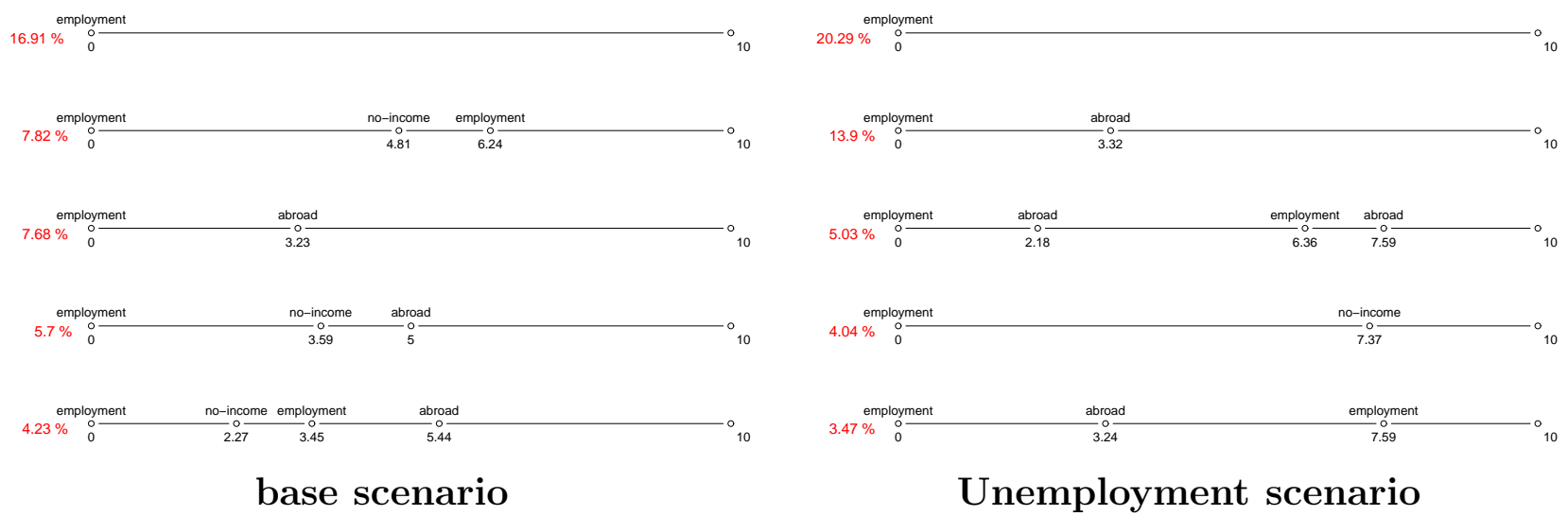

Unemployment scenario

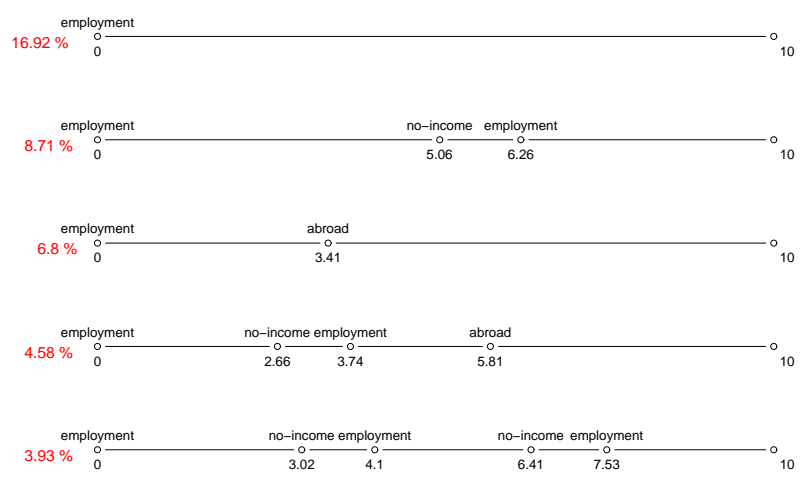

New EU scenario

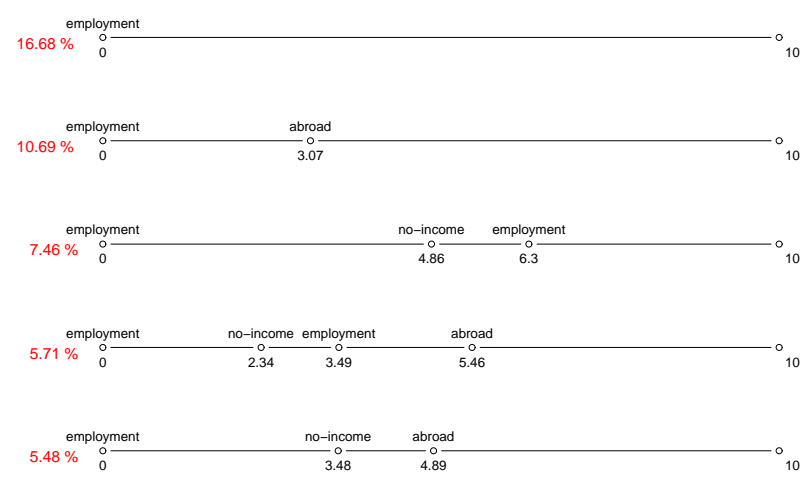

High income scenario

Figure 8: Most frequent paths in scenario's 